\title{
A pacificação como governo: as UPPs cariocas como dispositivos da governamentalidade global
}

Pacification as Government: Rio de Janeiro UPPs as Devices of Global Governmentality

\section{Introdução}

A conflitualidade no âmbito das cidades e seus impactos para a estabilidade internacional têm se tornado cada vez mais uma preocupação central para os estudos de segurança internacional e estudos da paz (NORTON, 2003; KOONINGS; KRUJIT, 2007; GRAHAN, 2016; MUGAAH; SAVAGE, 2012; NOGUEIRA, 2017). Isso decorre do fato de que o ritmo acelerado $^{3} \mathrm{e}$, muitas vezes,

1 Doutoranda em Ciência Política no Programa de Pós-Graduação em Ciência Política da Universidade Federal do Paraná (PPGCP-UFPR). Curitiba, PR, Brasil.

2 Professor Adjunto no curso de Relações Internacionais e Integração da Universidade Federal da Integração Latino-Americana (UNILA, Brasil). Foz do Iguaçu, PR, Brasil.

3 O relatório World urbanization prospects, publicado em 2018 pelo Departamento dos Assuntos Econômicos e Sociais (DESA) das Nações Unidas, constata que a população urbana mundial tem crescido de forma acelerada, passando de aproximadamente 750 milhões em 1950 - 30\% da população mundial - a 4,22 bilhões em 2018 - 55,3\% da população mundial. O relatório ainda apresenta a projeção de que a população urbana no mundo deve chegar a 6,8 bilhões em 2050, isto é, a 60\% da população mundial (UN, 2019s, p. 9). 
desregulado do crescimento das cidades ao redor do globo, ${ }^{4}$ e sua frequente associação com o aumento da desigualdade econômica e da violência nesses espaços, ${ }^{5}$ é percebido como um aspecto que não está limitado ao ambiente doméstico dos Estados. Muito pelo contrário, a violência nas cidades é frequentemente descrita como uma "nova forma de conflito", que se desenvolve no perímetro urbano e envolve a disputa pelo poder entre as autoridades do Estado e os atores violentos não estatais locais (GRAHAN, 2016, p. 33). Esse tipo de enquadramento posiciona a violência no âmbito da cidade como um fenômeno internacional descrito como o "novo urbanismo militar" (GRAHAN, 2016,, p. 26). Esse urbanismo militar "torna os espaços comuns e privados das cidades, bem como a sua infraestrutura - e suas populações civis - fontes de alvos e ameaças" (GRAHAN, 2016, p. 26). Dessa forma, a metáfora da guerra é frequentemente empregada pelos poderes públicos ao redor do globo como estratégia de enfrentamento à conflitualidade urbana. Esse tipo de racionalidade acaba por dar origem a formas de ingerência militarizadas nas cidades - as chamadas guerras assimétricas ou irregulares - centradas no combate e na vigilância de grupos insurgentes, terroristas e de organizações criminosas (GRAHAN, 2016, p. 27).

4 Mike Davis (2006, p. 16-17) chama atenção para o fato de que as favelas, frequentemente associadas à pobreza e à violência urbana, constituem-se em um fenômeno de caráter internacional na atualidade. Desde 1970, o crescimento de favelas em todo o sul ultrapassou o fenômenos da urbanização em si. De acordo com Davis, forças globais - como a mecanização da agricultura, a ocorrência de guerras civis, as dificuldades encontradas para a sobrevivência apenas por meio da agricultura familiar e a competição com o agronegócio em escala industrial - parecem empurrar as pessoas do campo para a cidade, mesmo quando a atração da cidade é enfraquecida por cenários de crise e ampla desigualdade econômica. O resultado desse rápido crescimento urbano em um contexto de desajuste estrutural, instabilidade econômica e redução do Estado tem sido a produção em massa de favelas, sobretudo nos países do sul global.

5 O relatório Urban violence and humanitarian challenges elaborado pelo Comitê Internacional da Cruz Vermelha (CICV) e pelo Instituto de Estudos de Segurança da União Europeia (EUISS) indica a negligência e marginalização, por parte dos Estados, com as populações que vivem em assentamentos urbanos ou favelas como causas para a violência urbana (APRAXINE et al., 2012, p. 27). Nesse mesmo relatório, é possível observar que isso ocorre, sobretudo, em decorrência da ausência do Estado nesses espaços e da marginalização constante dessas populações por parte da sociedade em geral, favorecendo a formação de grupos criminosos fortemente armados e a ocorrência cotidiana de confrontos entre gangues, facções criminosas e/ou narcotraficantes com agentes da lei para o controle do território (APRAXINE et al., 2012). 
Nesse contexto, uma nova categoria tem emergido nas narrativas sobre a construção da paz, a promoção do desenvolvimento e da segurança no mundo: o conceito de "cidades falidas" (MUGGAH; SAVAGE, 2012, p. 1). A ideia de cidade falida não é um enquadramento novo nas relações internacionais, uma vez que esse tipo de leitura está intrinsecamente relacionado à concepção de Estados falidos (HELMAN; RATNER, 1992). ${ }^{6}$ Assim, de forma análoga a essa discussão sobre o Estado, a ideia de cidade falida surge para compreender os efeitos da violência e das contestações sociopolíticas nas cidades para a promoção da segurança nas escalas nacional e internacional (MUGGAH, 2014, p. 3). Porém, mais do que isso, essa ideia acaba por definir a cidade como uma nova fronteira para a intervenção nacional e internacional, especialmente em contextos de não guerra (NOGUEIRA, 2017, p. 2). Logo, a noção de fragilidade associada às cidades estabelece um novo campo para a incidência de práticas que têm como objetivo diminuir e/ou reverter esse cenário de instabilidade no âmbito local (MUGGAH, 2014, p. 8).

Tendo isso em conta, o presente trabalho analisa como o conceito de cidade falida pode acabar por dar suporte à delimitação das cidades como um novo espaço de intervenção e de ingerência de uma governamentalidade global, ${ }^{7}$ direcionada às zonas periféricas das cidades que apresentam altos níveis de instabilidade securitária. Para evidenciar essa relação, o artigo se concentra na análise da política de pacificação promovida no Rio de Janeiro a partir do ano de 2008, sobretudo com a criação das unidades de polícia pacificadora (UPPs). O caso é analisado sob a luz das contribuições teóricas e conceituais desenvolvidas por Michel Foucault. Assim, os

6 Os Estados falidos são descritos como territórios nos quais as instituições e os processos políticos e econômicos que emanam dessas instituições acabaram por eclodir (HELMAN; RATNER, 1992, p. 3).

7 É importante distinguir a noção de governamentalidade global do termo governança global. A governança global pode ser definida como "atividades apoiadas em objetivos comuns, que podem ou não derivar de responsabilidades legais e formalmente prescritas e não dependem do poder de polícia para que sejam aceitas" (ROSENAU, 2000, p. 15). Assim, a governança global assume as práticas e racionalidades dominantes no espaço internacional como um dado adquirido, direcionando-se apenas a compreender seu funcionamento e sem necessariamente questionar as estruturas de poder subjacentes. A noção de governamentalidade global, ao contrário, possibilita desnaturalizar essas práticas a partir de uma leitura crítica sobre os regimes de pensamento que as conformam. 
conceitos de disciplina, governo e governamentalidade são centrais para a análise aqui proposta. $\mathrm{O}$ argumento central deste trabalho consiste na ideia de que as UPPs se constituíram em dispositivos de governo, altamente militarizados, que tinham como objetivo pacificar as favelas cariocas por meio da ocupação territorial desses espaços e do estabelecimento de um policiamento permanente. Por conseguinte, compreende-se que o conceito de cidade falida, aliado aos megaeventos sediados pelo Rio de Janeiro entre os anos de 2007 a 2016, favoreceram a construção da ideia de que a cidade do Rio de Janeiro constituía-se em uma necessidade urgente no que tange à questão securitária nacional e internacional e, portanto, como um espaço passível de intervenções que buscassem adequar a cidade para os Jogos Olímpicos. Dessa maneira, neste artigo, as UPPs não são entendidas apenas como iniciativas voltadas à diminuição da violência urbana e à promoção da segurança pública, mas como dispositivos de governo direcionados a moldar e adequar a cidade, sobretudo as favelas cariocas e a sua população.

A análise proposta neste artigo é operacionalizada por meio de uma metodologia qualitativa, utilizando-se de instrumentos como o método do estudo de caso, as técnicas de análise bibliográfica e a análise documental. As fontes da pesquisa são de duas naturezas: as fontes primárias, compostas por documentos relacionados à criação das UPPs, os discursos dos principais agentes públicos envolvidos nesse processo e entrevistas realizadas com os force commanders brasileiros no Haiti; e as fontes secundárias, compostas por artigos e livros que versem sobre a temática estudada. Para analisar o caso escolhido, o artigo está dividido em duas seções. A primeira seção apresentará como a concepção de governamentalidade auxilia na análise da noção de "cidades falidas" e de seus impactos nas formas de ingerências nas cidades. A segunda seção, por sua vez, analisa o caso do Rio de Janeiro a partir do arcabouço teórico e conceitual apresentado, problematizando as práticas e mentalidades de governo presentes nessa intervenção. 


\section{A governamentalidade global como forma de problematização das práticas e das racionalidades políticas internacionais}

Apesar de não ter como centro analítico a política internacional, as ferramentas teóricas e conceituais desenvolvidas por Michel Foucault podem certamente auxiliar na compreensão das práticas de intervenção no âmbito das cidades na atualidade, principalmente no tocante às novas formas de intervenção advindas da concepção do "novo urbanismo militar". Desse modo, as conceitualizações foucaultianas são compreendidas neste artigo como parte de uma "caixa de ferramentas" (Foucault, [1974]1994, p. 523-524), que podem ser instrumentalizadas por pesquisadoras de diferentes áreas visando compreender diversos fenômenos da vida social (NEAL, 2009, p. 162). Assim, os conceitos foucaultianos são empregados como uma lente analítica que permite que diferentes aspectos envolvidos na criação e implementação das unidades de polícia pacificadora (UPP) no Rio de Janeiro sejam problematizados, sobretudo no que diz respeito às práticas e racionalidades implementadas nas favelas cariocas por meio dessa política.

A abordagem foucaultiana é empregada por permitir a consideração das esferas internacional e doméstica na análise sobre as relações de poder concernentes à estratégia brasileira de pacificação da cidade do Rio de Janeiro. Essa estratégia de pacificação engendrou práticas que promoveram a militarização da gestão não apenas das favelas cariocas, como também das vidas das populações residentes nessas localidades. Nesse sentido, o entendimento foucaultiano de poder é essencial, uma vez que prioriza uma leitura sobre seu exercício, concentrando-se nas condutas e nos comportamentos por ele produzidos. Foucault entende o poder "como um relacionamento onde um tenta produzir, direcionar ou determinar os comportamentos de outros" (BLANCO, 2017, p. 91), presente em todas as relações sociais cotidianas (FOUCAULT, 1979, p. 8). Por conseguinte, essa forma de analisar o poder, por meio da observação das relações entre os sujeitos envolvidos, possibilita que a política de pacificação do Rio de Janeiro seja compreendida a partir da problematização das racionalidades que dão suporte e forma às 
práticas e aos mecanismos empregados pelos agentes envolvidos nesses processos.

Para que a análise das UPPs possa ser realizada, primeiramente é preciso compreender que o exercício cotidiano do poder conduz Foucault à análise das tecnologias de poder, que podem ser descritas como diferentes formas de conhecimento vinculadas a uma variedade de dispositivos mecânicos e a uma variedade de pequenas técnicas orientadas para produzir resultados práticos (ROSE, 2004, p. 52). Assim, as tecnologias de poder são responsáveis por conectar os variados tipos de conhecimentos, capacidades e métodos de julgamento, direcionando-os ao cumprimento de fins específicos (FOUCAULT, 1980, p. 122). A noção de dispositivo, por sua vez, é responsável por conceder unidade às tecnologias de poder observadas por Foucault. No entendimento foucaultiano, a noção de dispositivo se refere a um conjunto de elementos heterogêneos - como discursos, instituições, formas arquitetônicas, leis, proposições filosóficas e trabalhos científicos - direcionados a lidar com uma necessidade específica e tida como urgente (FOUCAULT, 1979 , p. 244). Para ser mais exata, dispositivo diz respeito "à disposição de uma série de práticas e de mecanismos (conjuntamente linguísticos e não linguísticos, jurídicos, técnicos e militares) com o objetivo de fazer frente a uma urgência e de conseguir um efeito" (AGAMBEN, 2005, p. 3). A concepção de normalização, por sua vez, diz respeito à forma por meio da qual uma necessidade urgente é conduzida e moldada em uma sociedade (BLANCO, 2017, p. 90). Assim, a normalização está estreitamente vinculada à percepção e à construção do que é entendido como "normal" ou "anormal" em uma sociedade. Muito sucintamente, o processo de normalização constitui-se na transformação dos elementos "anormais" que compõem a sociedade em elementos mais parecidos com o que se entende por "normal". Tal processo pode ocorrer tanto no âmbito 
individual, por meio da disciplina, ${ }^{8}$ quanto populacional a partir da

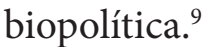

Sua concepção sobre as tecnologias de poder conduz Foucault a um entendimento distinto sobre o governo. Foucault compreende o governo como a "conduta da conduta" (FOUCAULT, [19771978]2008, p. 257). Assim, explora os dois sentidos da palavra conduta. Esta é, por um lado, entendida a partir do verbo "conduzir", indicando a ideia de guiar ou dirigir e, por outro, entendida a partir do substantivo "conduta", referindo-se às ações e aos comportamentos humanos (Foucault, [1977-1978] 2008, p. 258). Por conseguinte, o governo como "conduta da conduta" implica em qualquer tentativa deliberada de moldar os comportamentos dos indivíduos de acordo com conjuntos particulares de normas e para uma variedade de fins (DEAN, 2010, p. 18). Por esse ângulo, a análise do governo para Foucault está preocupada com os meios de cálculo que possibilitam seu exercício e com as formas de conhecimento que informam e dão sustentação a esse governo (GORDON, 1991, p. 10). Para dar mais inteligibilidade a esses processos, Foucault operacionaliza o conceito de governamentalidade, buscando, mais precisamente, dar visibilidade, por meio da ligação semântica entre as palavras governo e mentalidade, aos modos de pensamento e racionalidades envolvidas no exercício do governo (GORDON, 1991, p. 1). A governamentalidade, então, diz respeito ao que pode ser conhecido sobre o governo, ou seja, é a partir dela que se pode estudar a formação das práticas organizadas de pensamento por meio das quais se governa e se é governado (DEAN, 2010, p. 28).

8 A disciplina é operacionalizada por meio de um sistema de recompensas e punições, buscando corrigir os comportamentos daqueles indivíduos percebidos como desviantes em uma sociedade. Isso é feito por meio da fixação dos processos de treinamento (adestramento) e de controle permanente, para que, com base nisso, seja possível estabelecer a divisão entre aqueles considerados inadequados ou incapazes e os demais (FOUCAULT, 2007, p. 56).

9 A biopolítica difere da disciplina por ser aplicada ao homem como um ser vivo e não como um corpo (Foucault, [1976]2003, p. 242). Nesse sentido, enquanto a disciplina é exercida sobre o indivíduo, a biopolítica é exercida sobre a vida das populações. Essencialmente, a biopolítica objetiva a regulação e a administração da população, buscando moldar e orientar as condutas dos indivíduos que fazem parte da população (FOUCAULT, 2008, p.327). 
O amplo arcabouço de análise oferecido pela ideia de governamentalidade passou a ser introduzido por pesquisadores e pesquisadoras de relações internacionais como uma forma de compreender a crescente pluralidade das relações de poder na área. Assim, consolida-se o estudo sobre a governamentalidade global, que busca analisar como se conformam as práticas, técnicas, estratégias, conhecimentos e discursos na política internacional. Então, a ascensão de uma problematização das relações internacionais sobre a governamentalidade está relacionada com a crescente necessidade de se entender e de se explicar as diversificadas técnicas internacionais de governança e como elas incidem sobre Estados e suas populações. Desse modo, a operacionalização da noção de governamentalidade para a análise da política internacional permite que esta seja estudada como um domínio essencialmente social, composto por práticas e racionalidades políticas orientadas para objetivos específicos (SENDING; NEUMANN, 2006, p. 678). A partir disso, é possível problematizar os conjuntos de racionalizações, teorizações e conhecimentos técnicos ligados aos meios estabelecidos para moldar e reformular as condutas, as práticas e as instituições presentes na política internacional (ROSE, 2004, p. 20).

A governamentalidade global é uma importante ferramenta analítica que permite compreender as técnicas utilizadas para moldar e até mesmo constranger a conduta dos atores no âmbito internacional. Isso é possível porque a noção de governamentalidade possibilita desnaturalizar essas práticas a partir de uma leitura crítica sobre os regimes de pensamento que as conformam. Isso pode ser feito porque o estudo sobre a governamentalidade explora o governo - entendido em termos foucaultianos não como algo assente nas estruturas institucionais, mas, sim, como "a conduta da conduta" - para além de seus aspectos institucionais e investiga como as dimensões discursivas do poder se manifestam nos imaginários políticos e nas racionalidades políticas que orientam a práxis (ZANOTTI, 2013, p. 238). Assim, a governamentalidade global estuda como se desenham as conexões entre os instrumentos de conhecimento e as práticas governamentais vigentes, bem como 
as consequências não intencionais desses esforços. Isso é possível porque os estudos sobre a conformação de uma governamentalidade focam na identificação das "mentalidades" de governo presentes nas diferentes formas de se governar (NEUMANN; SENDING, 2010, p. 9). Dessa maneira, a governamentalidade conecta a prática do governo, de conduzir condutas, às formas sistemáticas de pensamento e conhecimento que o integram e o tornam operacional.

No tocante aos estudos da paz e à segurança internacional, a lente analítica da governamentalidade tem sido empregada, principalmente, com o objetivo de analisar e desnaturalizar as racionalidades políticas presentes nas práticas internacionais de estabilização de cenários de crise (DEAN, 1999; ZANOTTI, 2008), de ajuda humanitária (DUFFIELD, 2005; ZANOTTI, 2013) e de construção da paz em países pós-conflito (ZANOTTI, 2011; JABRI, 2013; BLANCO, 2020). Essas análises tanto se direcionam a compreender a já tradicional atuação de organizações internacionais e de Estados em contextos de instabilidade securitária interna ou internacional, como se voltam à observação da crescente participação de organizações não governamentais (ONGs) nesses processos. Nesse contexto analítico, Mark Duffield (2005, p. 2) problematiza a centralidade de uma racionalidade política liberal ${ }^{10}$ presente nas práticas internacionais de construção da paz e ajuda humanitária. Para Duffield, isso ocorre porque, com o fim da Guerra Fria, os conceitos de desenvolvimento e segurança passam a estar cada vez mais interconectados no vocabulário político internacional. ${ }^{11}$ Em decorrência disso, é crescente a percepção de que situações que antes eram consideradas problemas internos dos países - como os conflitos

10 O liberalismo, dentro de uma abordagem foucaultiana, deve ser entendido como uma prática, uma maneira de se "fazer as coisas" (FOUCAULT, 2008, p. 318) - uma racionalidade de governo.

11 Esse tipo de racionalidade pode ser observada no relatório Global peace index 2019: measuring peace in a complex world, que defende que o aumento nos índices de paz positiva está diretamente associado ao desenvolvimento econômico, observando que o crescimento no PIB de um país é correlato ao aumento da paz positiva (IEP, 2019, p. 77). O relatório da Organização das Nações Unidas intitulado Transforming our world: the 2030 agenda for sustainable development defende que o desenvolvimento (sustentável) não pode ser alcançado sem paz e segurança. A organização ressalta a necessidade urgente de se corrigir os fatores que dão origem à violência, como desigualdade, corrupção, má governança e fluxos financeiros e de armas ilícitos (UN, 2015, p. 13). 
civis, o crescimento acelerado da população urbana, acompanhado do aumento da pobreza e da desigualdade e o aumento da violência em situações de não guerra - agora se constituem em ameaças à estabilidade internacional (DUFFIELD, 2005, p. 3). A segurança, então, não é mais apenas um objetivo que deve ser perseguido somente pelos instrumentos internacionais convencionais de estabilização de cenários pós-conflito, que envolvem a ocupação militar e o controle político sobre o processo de reconstrução dos países afetados por conflitos armados. Dentro dessa conjuntura, a promoção da segurança no mundo engloba a criação de mecanismos que incidem sobre os mais diversos aspectos da vida social e política dos Estados, como a natalidade da população, a expectativa de vida em um local, a mobilidade interna e internacional, a desigualdade entre classes, gêneros e raças, o nível de escolaridade de uma população e o combate ao crime e à violência. Em consequência, a segurança transforma-se em uma problemática liberal, que pode ser descrita como a preocupação com a vida biológica e com todos os processos de controle e gerenciamento relacionados à população e à economia (DUFFIELD, 2005, p. 4). Portanto, a segurança é cada vez mais uma questão de biopolítica e disciplinamento das populações de países considerados “instáveis" e "pouco desenvolvidos" de acordo com as normas de conduta da sociedade internacional ${ }^{12}$ e com as necessidades da economia capitalista.

A segurança enquanto um problema de ordem liberal é importante para este artigo, uma vez que ela tende a ampliar as formas de intervenção internacionais para a construção da paz, bem como as localidades passíveis dessas intervenções. Durante a década de 1990, as operações de paz e intervenções humanitárias concentravam-se majoritariamente em (re)construir as instituições políticas

12 Atualmente, as democracias liberais ocidentais são compreendidas como o modelo de Estado "normal" ou mesmo ideal nas relações internacionais. Desse modo, não é nenhuma surpresa que as intervenções internacionais de construção da paz, descritas como multidimensionais, entendam que uma paz sustentável somente poderá ser alcançada por meio da construção de instituições políticas e econômicas (neo)liberais nos Estados pós-conflito intervindos (BLANCO, 2017, 2020). 
e econômicas do Estado, ${ }^{13}$ de forma direta, após a ocorrência de um conflito armado. No entanto, com o avançar dos anos 2000, é possível perceber a modificação no modus operandi dos atores internacionais nesse campo. A atuação dos agentes internacionais está cada vez mais pautada em intervenções indiretas, que incidem sobre os países da periferia global por meio de condicionalidades, do estabelecimento de quais são as "melhores práticas" nas mais determinadas áreas da vida social e política e da criação de índices e relatórios de avaliação de cenários e políticas públicas. ${ }^{14}$ Organizações internacionais como o Fundo Monetário Internacional, o Banco Mundial e a própria Organização das Nações Unidas dão exemplos desse tipo de atuação indireta. Essas instituições fomentam a formação de uma densa rede de normas e regras liberais buscando conduzir os comportamentos não apenas dos Estados, mas de outras organizações políticas - como ONGs, por exemplo - e também dos indivíduos (JOSEPH, 2010, p. 233). Desse modo, as racionalidades políticas internacionais cada vez mais passam a ser incorporadas internamente pelos Estados como forma de adequação aos padrões de conduta tidos como normais.

Assim, a análise sobre a conformação de uma governamentalidade voltada à esfera de segurança internacional contribui para a problematização das práticas e das racionalidades políticas internacionais - desnaturalizando processos e dinâmicas que são, muitas vezes, percebidos como naturais. Isso ocorre porque a governamentalidade conduz a pesquisadora a questionar quais os quadros discursivos e normativos dão sustentação e orientação às práticas organizadas de se fazer as coisas. Portanto, para que se possa observar e analisar o exercício de governo, deve-se investigar quais são os quadros discursivos que dão sustentação a ele. Isso é importante porque a governamentalidade opera, orienta e constrói

13 A prática mais comum é a de statebuilding, que pode ser definida como o processo por meio do qual são construídas ou reconstruídas por agentes internacionais as instituições de governança de um Estado, responsáveis por proporcionar a segurança física e econômica dos cidadãos (CHANDLER, 2006, p. 1). O caso do Kosovo, do Timor-Leste e do Iraque são exemplos clássicos de statebuilding.

14 Para compreender melhor essas transformações nas formas de intervenção internacional, ver Chandler (2006). 
significações a respeito do internacional a partir de centros de produção de conhecimento teórico, técnico e econômico sobre as dinâmicas relacionais dos atores internacionais. Nesse seguimento, e especificamente para este artigo, a dimensão de análise da governamentalidade, preocupada com o estudo sobre a conformação de uma racionalidade política, possui centralidade para compreender como as noções de "falência" e "fragilidade" aplicadas às cidades dão sustentação à conformação de um novo "urbanismo militar" - refletindo, ainda que indiretamente, na criação das unidades de polícia pacificadora (UPPs) no Rio de Janeiro.

$\mathrm{O}$ enquadramento das cidades a partir da perspectiva da governamentalidade global é possível porque as cidades se constituem em espaços que envolvem dinâmicas que são, simultaneamente, localizadas e globalizadas. Por conseguinte, o cotidiano das cidades é, ao mesmo tempo, produto de suas características locais e reflexo da interação desse local com a esfera internacional. Como consequência dessa dinâmica, as fronteiras entre a cidade e a esfera internacional se tornam cada vez menos fixas e delimitadas, aumentando a permeabilidade local às racionalidades e práticas políticas fomentadas por agentes externos. É importante destacar que a absorção dessas práticas e racionalidades políticas internacionais é feita de acordo com as características particulares de cada cidade. Assim, a cidade, por um lado, engloba as particularidades e as necessidades de um contexto social e político específico (o seu) e, por outro lado, está inserida em uma ordem de classificação e organização sociopolítica global (MAGNUSSON, 2011, p. 4-5). Nesse contexto analítico, a ascensão do conceito de cidade falida compõe um quadro epistêmico e normativo que colabora e dá suporte com o surgimento de práticas de governo, direcionadas a disciplinar e a moldar a vida nas cidades. Portanto, o referencial da falência das cidades não se restringe apenas ao campo ideacional, mas acaba por possibilitar que a cidade - ao ser considerada falida - seja entendida como uma necessidade de segurança interna e internacional, dando origem a regimes de práticas criados especificamente para lidar com a insegurança securitária nesses espaços. 
A ideia de cidade falida não se constitui, exatamente, em um entendimento inovador nos estudos sobre a segurança internacional, uma vez que está intrinsecamente vinculada à concepção de Estados falidos (HELMAN; RATNER, 1992). Os Estados falidos são descritos como territórios nos quais as instituições e os processos políticos e econômicos que emanam dessas instituições acabaram por implodir (SORENSEN, 1999, p. 9; ROTBERG, 2002, p. 3-5). Em razão disso, esses Estados teriam se convertido em espaços profundamente conflituosos, com altos níveis de pobreza, com baixa legitimidade administrativa e, consequentemente, em ameaças potenciais à estabilidade internacional (ROTBERG, 2002, p. 2). Esse enquadramento está embasado na concepção de que o Estado, sozinho, deve fornecer a segurança efetiva do território por meio da manutenção do monopólio do uso da força e do controle da lei (MAGNUSSON, 2011, p. 31). Aqueles Estados que não conseguem minimamente cumprir com esses requisitos são descritos como espaços não governáveis e com potencial de abrigar grupos terroristas, grupos paramilitares e organizações criminosas (ARSENAULT; BACON, 2014, p. 87). Desse modo, é crescente a compreensão de que a incapacidade de manter sua estabilidade e legitimidade interna transforma um Estado em uma ameaça - em potencial - para a comunidade internacional, uma vez que este pode exportar insegurança e criminalidade para outros Estados (FUKUYAMA, 2005, p. 2). A conceitualização que versa sobre a falência estatal não está restrita ao campo teórico da segurança internacional, uma vez que se converteu em um quadro discursivo capaz de produzir efeitos práticos. Dessa maneira, o quadro discursivo do Estado falido informa e sustenta práticas específicas de governo internacionais direcionadas a moldar e normalizar o comportamento dos Estados - como as operações de paz da ONU e os processos de statebuilding. ${ }^{15}$

A ideia de cidade falida, de modo similar à noção de Estado falido, surge como uma tentativa de explicar, de modo sistemático, quais

15 Para ver mais sobre esse tipo de práticas, ver Blanco (2014). 
são os efeitos produzidos pela crescente violência nas cidades para a estabilidade institucional em âmbito nacional e para a segurança regional e internacional (MUGGAH, 2014, p. 3). Por conseguinte, a ascensão do conceito de cidades falidas denota uma nova configuração semântica, que possibilita que práticas e entendimentos de intervenção internacionais sejam transferidos e aplicados a uma nova esfera de atuação: a cidade (MIKLOS; PAOLIELLO, 2017, p. 546). Assim, a adição da concepção de falência ao estudo sobre as cidades possibilita a análise sobre a operacionalização de uma governamentalidade global no nível local. Essa governamentalidade incide sobre as cidades e suas populações a fim de moldar seus comportamentos de acordo com uma expertise e com uma racionalidade política própria, que é essencialmente liberal. De acordo com Robert Muggah (2012, p. 1), os centros urbanos considerados frágeis são aqueles nos quais o contrato social estabelecido entre as autoridades do Estado e os cidadãos se encontra em crise ou deixou de existir. ${ }^{16}$ Consequentemente, esses lugares são marcados por altos índices de violência, pelo descumprimento dos direitos humanos em larga escala e pela crescente desconfiança com as instituições públicas (MIKLOS, 2017, p. 548).

Inicialmente, o conceito de cidade falida estava atrelado à preocupação com países marcados pela ocorrência de conflitos armados. Assim, nesse primeiro momento, a conexão entre a cidade e a fragilidade institucional era feita por meio da problematização dos conflitos ocorridos no perímetro urbano e pela associação às situações de fragilidade do Estado (MUGGAH; SAVAGE, 2012, p. 4). Por conseguinte, o que estava sendo investigado era, sobretudo, a relação entre a falência estatal (pela contestação de grupos internos) e a fragilidade urbana. Dessa maneira, as pesquisas e

16 O Instituto Igarapé em conjunto com a Universidade das Nações Unidas, com o Fórum Econômico Mundial e com a iniciativa "100 Cidades Resilientes" desenvolveram uma plataforma de dados que mapeia a fragilidade das cidades ao redor do mundo. A plataforma inclui informações a respeito de cerca de 2.100 cidades com populações de 250.000 ou mais. As cidades foram classificadas a partir de onze variáveis e receberam uma pontuação entre 1 e 4, sendo 4 o nível concedido às cidades em situação mais críticas. As variáveis variam do crescimento populacional da cidade, desemprego e desigualdade à poluição, riscos climáticos, homicídios e exposição ao terrorismo (IGARAPÉ, 2020, s.p.). 
as conceitualizações desenvolvidas direcionavam-se a pensar em políticas e práticas que poderiam ser aplicadas às cidades e Estados considerados frágeis ou falidos. Essas análises pretendiam, em sua maioria, compreender como a dimensão urbana influenciava a estabilização de territórios em conflito ou pós-conflito - sendo que esses conflitos deveriam ser internacionalmente reconhecidos. Portanto, o papel da cidade era compreendido a partir da existência de uma condição de conflito ou pós-conflito, buscando refletir sobre qual a importância da violência urbana e estabilidade administrativa da cidade nesses contextos.

Paulatinamente, a perspectiva que associa a falência urbana à falência estatal passa a conviver com uma nova abordagem, preocupada com os cenários nos quais há paz formal. ${ }^{17}$ Esse alargamento dos estudos sobre as cidades falidas para além das zonas de ocorrência de conflitos formais possibilitou que regiões anteriormente ausentes ou menos frequentes na abordagem passassem a ser estudadas. Dessas regiões, a América Latina ${ }^{18}$ recebe especial atenção por abrigar cidades que apresentam altos índices de violência, mesmo não havendo conflitos armados ativos no continente. Tendo esse contexto em consideração, os pesquisadores Keer Koonings e Dirk Krujit (2007, p. 2) elaboraram a expressão "cidades fraturadas" para evidenciar a duradoura "síndrome de pobreza, informalização do trabalho, desigualdade e exclusão social" observada nos grandes centros urbanos latino-americanos. Tal síndrome amplia e reforça as tradicionais clivagens sociais latino-americanas, transformando a pobreza e a desigualdade nos grandes centros urbanos em um fenômeno sistêmico da região. Os efeitos dessa conjuntura constituem-se na fragmentação social e espacial das cidades latino-americanas, uma vez que a pobreza e a violência são associadas a

17 Localidades nas quais não há um conflito formalmente ativo entre Estados ou entre Estado e grupos contestadores - paz negativa (GALTUNG, 1969).

18 De acordo com o levantamento de 2018 do Instituto Igarapé, a América Latina é a região mais violenta do mundo, somando 39\% dos homicídios mundiais e concentrando 41 das 50 metrópoles mais perigosas (INSTITUTO IGARAPÉ, 2018, s.p.). A região é a única do mundo onde a principal causa externa de morte é o homicídio (52\% dos falecimentos). Uma em cada cinco pessoas mortas violentamente em 2012 era brasileira, colombiana ou venezuelana. 
bairros ou distritos específicos. Estes últimos tornam-se estigmatizados como áreas proibidas, enquanto seus habitantes são por sua vez estigmatizados como "indesejáveis" (KOONINGS; KRUJIT, 2007, p. 5). Como resultado, a maioria das aglomerações urbanas latino-americanas é, por um lado, estruturalmente excluída dos circuitos de consumo urbano e, por outro lado, transformada em alvos rotineiros das forças policiais.

Oliver Jütersonke, Robert Muggah e Dennis Rodgers (2009, p. 3-4) também analisam a violência das cidades latino-americanas de forma sistêmica, dando centralidade à identificação de quem são os atores responsáveis por sua ocorrência - os denominados atores violentos. Nesse contexto, os grupos ligados ao crime organizado, às gangues e, mais recentemente, às milícias passam a ser compreendidos como "novas urgências urbanas" (JÜTERSONKE; MUGGAH; RODGERS, 2009, p. 4). Isso ocorre porque, de acordo com esse enquadramento, os atores violentos, ao atuar nas grandes cidades, constituem-se em ameaças no nível local, nacional, regional e transnacional. Essa escalada nos níveis de percepção da ameaça representada por esses atores acaba por suscitar políticas de enfrentamento à violência cada vez mais ostensivas e repressivas, envolvendo tanto o tradicional uso das forças policiais como o emprego do poder militar em regiões periféricas. Todavia, essas táticas repressivas empregadas com o objetivo de combate à criminalidade tendem a fomentar a sofisticação da atuação dos grupos violentos e, consequentemente, a aprofundar a fragilidade da cidade.

Observa-se que as cidades, consideradas como falidas, são compreendidas cada vez mais como áreas “ingovernáveis" e dominadas por atores violentos. Esse tipo de mentalidade está muito presente nos meios de comunicação e na ampla visibilidade concedida aos efeitos da violência nos grandes centros urbanos. ${ }^{19}$ A representação da violência e da insegurança nessas cidades na mídia reforça a percepção de que elas são uma preocupação compartilhada

19 Para ler mais sobre a relação existente entre as narrativas produzidas pela mídia no Brasil e a violência estrutural no país, ver Sodré (2006, p. 33-42). 
entre a sociedade doméstica e internacional. ${ }^{20}$ Esse fato fortalece a ideia de que a violência nas cidades é uma necessidade urgente e, portanto, demanda a intervenção dos poderes públicos a partir da criação de dispositivos de governo destinados a lidar com o problema da violência urbana. Dentro desse tipo de leitura sobre a vida social, entende-se que a ação dos atores violentos não é pautada pela mesma racionalidade dos agentes públicos e que, segundo a abordagem, tende a utilizar de mecanismos insurgentes ou criminosos para estabelecer seu domínio (MUGGAH, 2014, p. 2). Essa forma de atuação faz com que essas cidades sejam percebidas não mais apenas como ameaças locais ou problemas internos dos Estados, mas, sim, como ameaças em potencial para o meio internacional. Esse enquadramento possibilita que o conceito de cidade falida tenha uma aplicação prática e converta-se em um aspecto da governamentalidade global - informando e dando sustentação ao governo como "conduta da conduta". Além disso, a crescente associação do conceito às práticas dos atores internacionais possibilita que ele seja incorporado por racionalidades de governo internacionais - como as práticas e técnicas de intervenção em Estados pós-conflito. A concepção de cidade falida provoca, assim, uma modificação nos quadros discursivos internacionais que compõem o governo, como "conduta da conduta", e, a partir disso, fomenta a criação de novas práticas ou desloca a esfera de atuação das práticas de governamento já existentes no cenário internacional.

Uma das consequências desse tipo de enquadramento a respeito das cidades - a partir da ideia da falência e da fragilização das suas instituições políticas e administrativas - é a crescente modificação na gestão da segurança urbana de acordo com o "novo urbanismo militar” (GRAHAN, 2016, p. 26). Por conseguinte, é possível observar uma transição no modo como se dá o uso militar e civil

20 Em 2016, o jornal britânico The Economist publicou uma lista com as cidades mais violentas do mundo em 2015, na qual demonstrava preocupação com os altos índices de homicídios e violência das maiores cidades da América Latina e da África (THE WORLD'S..., 2016, s.p.). Já no ano de 2017, a publicação britânica voltou a demonstrar preocupação com as altas taxas de homicídio em centros urbanos da América do Sul e a sua vinculação com o tráfico internacional de drogas e entorpecentes (THE WORLD'S..., 2017, s.p.). 
da tecnologia, que passa cada vez mais a atuar "entre a vigilância e o controle da vida cotidiana nas cidades ocidentais e as agressivas guerras de colonização" (GRAHAN, 2016, p. 26). Na atualidade, é notória a militarização de uma ampla gama de debates sobre a política interna, sobre as paisagens urbanas e sobre o circuito de infraestrutura das cidades, além da própria lógica de gestão da vida das populações no âmbito das cidades. Assim, é crescente a percepção de que a cidade não é mais apenas o espaço, mas o próprio meio da guerra na atualidade. Dessa forma, ela acaba sendo incorporada nas doutrinas militares como o centro de um amplo espectro de insurgências transnacionais que atuam sobre redes sociais, culturais, políticas e financeiras, convertendo-se em um risco ao modo de vida das sociedades ocidentais (GRAHAN, 2016, p. 73). Aqui é possível observar que a conceitualização de cidade falida permeia a construção de um imaginário social de quais são os atores passíveis de intervenção - cidade e periferia. Em tal conjuntura, noções como guerra urbana, operações militares em áreas urbanas ou conflitos de baixa intensidade ${ }^{21}$ estão cada vez mais presentes nas agendas de segurança nacionais e internacionais.

Nesse contexto, os conceitos domésticos e internacionais de cidade tendem a convergir - entendendo as cidades como comunidades fechadas que devem ser asseguradas e protegidas do "outro" ameaçador (CHOW, 2006, p. 42). Esses quadros normativos compõem a ideia de guerra como um exercício permanente, colocando operações militares e de alta tecnologia como a resposta mais adequada aos atores não estatais contestadores da ordem política e social (GRAHAN, 2016, p. 80). O urbanismo militar, portanto, acaba por dar origem a práticas específicas de governamento das cidades em escala global, caracterizadas pela crescente militarização da vida dentro espaço urbano. Tal militarização da vida faz com que a diferenciação entre quem é "combatente" e quem é "alvo"

21 Esse tipo de conflito também é designado como "guerra de quarta geração", marcada pelo desenvolvimento de um conflito assimétrico ou não convencional - no qual se opõem às forcas tradicionais do Estado, grupos insurgentes, guerrilheiros, terroristas e até mesmo organizações criminosas (HAMMES, 2006, p. 202). 
da violência se torne nebulosa e, muitas vezes, irrealizável. O resultado, frequentemente, é a instauração de políticas de repressão e de segregação social do espaço urbano. Nesse sentido, percebe-se que a criação do Programa de Polícia Pacificadora no Rio de Janeiro, como uma forma de resposta ao domínio de grupos criminosos das favelas cariocas, está inserida dentro desse padrão internacional de governamento do espaço urbano. Tendo isso em conta, a próxima seção analisa as práticas e racionalidades presentes nas UPPs cariocas.

\section{Rio de Janeiro: da "cidade partida" à implementação do dispositivo de pacificação das favelas cariocas}

Esta seção analisa como a política de pacificação das favelas cariocas está relacionada às práticas e às racionalidades de governo, como condução das condutas internacionais no tocante à segurança no âmbito das cidades. Para isso, inicialmente, é importante destacar que uma reflexão sobre as unidades de polícia pacificadora (UPPs) demanda que as características dos espaços e dos grupos sociais atingidos por essa política sejam analisadas, assim como a relação entre essa política e as racionalidades do Estado brasileiro e o quadro normativo local e internacional ao qual ela está circunscrita. As UPPs são entendidas como um dispositivo de governo militarizado que incidiu nas favelas cariocas visando à pacificação desses territórios por meio de uma gestão baseada em técnicas de disciplinamento das suas populações ${ }^{22}$ a partir do seu policiamento constante. A relação das UPPs com a governamentalidade global está justamente na militarização das respostas dos poderes públicos à presença de atores violentos no âmbito das cidades.

Como consequência, compreende-se neste trabalho que a estratégia de pacificação do Rio de Janeiro enquadra-se dentro do novo urbanismo militar - que incide sobre a vida das cidades por meio de sua militarização. Para além disso, a pacificação das favelas cariocas está relacionada à experiência brasileira na Missão das

22 Para ler mais sobre as UPPs como dispositivos disciplinares que incidiam sobretudo sobre a população periférica no Rio de Janeiro, ver Leite et al. (2018). 
Nações Unidas para Estabilização no Haiti (MINUSTAH), ${ }^{23}$ uma vez que envolve racionalidades políticas e conhecimentos técnicos adquiridos pelas Forças Armadas brasileiras no enfrentamento à violência urbana em Porto Príncipe. É importante destacar que este trabalho, ao abordar a relação entre as UPPs e a experiência brasileira no Haiti, não propõe a realização de uma análise sobre transferência de política pública. ${ }^{24} \mathrm{O}$ artigo se concentra em problematizar como as racionalidades vinculadas às práticas adotadas no Haiti e no Rio de Janeiro pelas autoridades brasileiras - principalmente relacionadas à ideia de pacificação - estão conectadas com um quadro discursivo mais amplo e internacionalmente localizado. Portanto, o objetivo central desse trabalho não é apenas observar como determinadas práticas de intervenção securitária no espaço urbano foram transferidas do Haiti para o Rio de janeiro ou vice-versa. O foco dessa pesquisa é conectar as práticas brasileiras, no tocante à gestão de zonas e populações periféricas no âmbito das cidades, às práticas internacionais de controle militarizado da vida nas cidades. Em essência, busca-se desnaturalizar a crescente militarização das respostas dadas pelo país aos problemas de segurança no âmbito das cidades, como também o tratamento destinado às populações periféricas cariocas, por meio do resgate histórico do significado do termo pacificação.

De início, é preciso analisar, por um lado, como se dá a construção da percepção do Rio de Janeiro como uma cidade "em conflito" constante entre a favela e o asfalto e, por outro lado, o fortalecimento da concepção de que a fragilidade local poderia ser resolvida ou ao menos dirimida por meio da militarização das técnicas de gestão do espaço urbano. As favelas surgiram na cidade do Rio de Janeiro na última década do século XIX, a partir da campanha pela reforma urbana centrada na demolição dos cortiços cariocas (OLIVEIRA, 2014, p. 132). Nesse processo, muitos moradores optaram por se

23 Em ingles, United Nations Stabilisation Mission in Haiti (UNSTAMIH).

24 Para ler mais sobre como ocorrem os processos de transferência e difusão de políticas públicas em um mundo cada vez mais globalizado e regionalizado, ver Evans e Davies (1999), Dolowitz e Marsh (2000), Stone (2004), Dolowitz (2017). Para ler mais sobre o processo de transferência de conhecimento do Rio de Janeiro para o Haiti, ver Yazdani, Bercovitch e Charles-Voltaire (2014). 
instalar nas encostas do centro da cidade - mais próximas dos seus postos de trabalho - a seguir para os subúrbios e/ou regiões metropolitanas (OLIVEIRA, 2014, p. 132). Nesse contexto, o Morro da Providência e o Morro de Santo Antônio foram as primeiras favelas cariocas. Todavia, não tardou para que as favelas se expandissem para outras zonas da cidade, próximas aos bairros de classe média alta da zona sul. ${ }^{25}$ Desse modo, a proximidade espacial entre as favelas e os bairros de classe média terminou por se tornar uma característica central da cidade do Rio de Janeiro, constituindo-se, simultaneamente, em atrativo cultural e fonte de insegurança. Essa visão contraditória sobre as favelas é possível porque estas são lócus de características culturais internacionalmente reconhecidas - associadas à cultura negra e a ritmos como o samba e o funk -, mas também amplamente associadas ao controle armado dos grupos vinculados ao tráfico de drogas (OLIVEIRA, 2014, p. 134). Essas características fazem com que a ideia de "favela" seja, por um lado, um conceito que está constantemente presente nos imaginários culturais e sociais sobre a cidade do Rio de Janeiro e, por outro, converta-se em um elemento de segregação espacial e social. Nesse sentido, desde o início do século XX, tem início a compreensão da favela como um problema a ser extinto ou pelo menos controlado no âmbito de seu crescimento populacional entre os poderes públicos.

Desde a década de 1990, o Rio de Janeiro tem sido descrito por autoridades políticas, veículos da mídia brasileira e pela sociedade em geral como um ambiente altamente violento, sobretudo em razão dos constantes confrontos entre as organizações criminosas ligadas ao tráfico de drogas - e as forças policiais cariocas (SILVA; LEITE, 2008). De acordo com dados da Secretaria de Segurança

25 De acordo com o Data Rio, em 2018, a cidade do Rio de Janeiro contava com 1.018 favelas, as quais possuíam cerca de 1.434 .975 de habitantes - totalizando $22 \%$ da população carioca (DATA RIO, 2020, s.p.). 
Pública do Rio de Janeiro, a taxa de letalidade violenta ${ }^{26}$ na capital carioca no ano de 2004 era de 57,2 a cada cem mil habitantes; já no ano de 2007, no qual ocorreriam os Jogos Pan-Americanos do Rio de Janeiro, a taxa de letalidade violenta ainda se encontrava no alarmante número de 54,3 a cada cem mil habitantes (ROLIM, 2020 , p. 4). As taxas preocupantes de violência são ainda historicamente acompanhadas por altos índices de corrupção e instabilidade política no Rio de Janeiro, ${ }^{27}$ gerando uma crescente insatisfação e desconfiança em relação aos poderes públicos no estado e na capital do Rio de Janeiro.

Por conseguinte, não é surpresa que a ideia do Rio de Janeiro como uma cidade partida (VENTURA, p. 1994, p. 02) consolidou-se como uma forma de entender e explicar os impactos gerados pelas contradições sociais existentes na cidade para a precarização de sua situação securitária. No livro, José Mariano Beltrame, secretário de Segurança Pública do estado do Rio de Janeiro durante o período de idealização e implantação da política de pacificação das favelas cariocas, recorre exatamente a esse termo - cidade partida para enfatizar as dificuldades encontradas por ele ao chegar ao Rio de Janeiro. Essa percepção fica evidente quando Beltrame (2014, p. 68) relata que ficou "imediatamente impressionado ao constatar que o Rio era mesmo uma cidade partida", na qual "por toda a cidade havia áreas geograficamente dominadas por criminosos em que o Estado não entrava”. A inclusão do termo cidade partida no

26 De acordo com os dados da Secretaria de Segurança Pública, a categoria letalidade violenta "corresponde ao somatório dos seguintes títulos: homicídio doloso, roubo seguido de morte (latrocínio), lesão corporal seguida de morte e morte por intervenção de agente do Estado" (ROLIM, 2020, p. 20).

27 Em 2019, o Brasil obteve a nota 35 de 100 no relatório The corruption perceptions index 2019, ocupando a posição $106^{\circ}$ entre os 180 países analisados (TRANSPARENCY INTERNATIONAL, 2019, p. 3). Essa nota é a mais baixa da série histórica brasileira, indicando a piora na percepção pública sobre a corrupção no país. Dentro desse contexto, o estado do Rio de Janeiro é marcado por inúmeros casos de corrupção na esfera pública. Desvio de recursos públicos, recebimento de propina, lavagem de dinheiro e participação em organização criminosa são alguns dos delitos pelos quais representantes públicos do Rio foram condenados ou acusados na última década. Tal fato fica explícito ao se observar que cinco ex-governadores do Rio de Janeiro foram presos ou pelo menos indiciados nos últimos três anos: Moreira Franco, Anthony Garotinho, Rosinha Garotinho, Sérgio Cabral e Luiz Fernando Pezão. Além da corrupção política, o estado ainda conta com o crescimento das milícias como um poder paralelo ao Estado e altamente violento 
relato de Beltrame sobre sua experiência no Rio de Janeiro fortalece a concepção pré-existente de que o Rio de Janeiro se constitui em uma cidade dividida entre morro e asfalto e marcada pela persistente (e quase irremediável) existência de um "conflito constante" entre a área nobre da cidade e as áreas pobres - as favelas cariocas.

Essa caracterização do Rio do Janeiro como uma cidade partida favoreceu a ascensão de uma narrativa que não apenas separa a cidade social e geograficamente entre a favela e o asfalto, como também terminou por justificar a criação de políticas de segurança cada vez mais ostensivas e violentas. ${ }^{28}$ Isso ocorre porque esse entendimento sobre a cidade do Rio de Janeiro estabelece uma separação geográfica e social entre a população do asfalto e a população da favela, de modo a alocar o foco da violência nas favelas (MORAES et al., 2015, p. 495). Nesse sentido, as populações do "asfalto" são frequentemente apontadas como as vítimas da violência e da insegurança, enquanto as populações dos morros são tidas como responsáveis por essa violência. Assim, a "representação do Rio de Janeiro como uma 'cidade partida' terminou [...] por reforçar os nexos simbólicos que territorializam a pobreza e a marginalidade nas favelas cariocas" (LEITE, 2000, p.74). Além disso, a noção de cidade partida constrói uma lógica de conflito entre as áreas do asfalto e as áreas das favelas, legitimando processos de intervenção e repressão nos espaços compreendidos como polos dessa violência. Com isso, não se busca negar os efeitos da violência na capital fluminense, mas chamar atenção para o fato de que a percepção de que o Rio de Janeiro está em constante conflito é uma construção narrativa, a qual está pautada em interesses econômicos e políticos.

28 Durante os anos de 1995 e 2000, os policiais militares e civis do estado do Rio de Janeiro que praticassem atos classificados, pelo comando da corporação, como "de bravura" - que, majoritariamente, resultavam na morte de supostos criminosos sem um julgamento adequado - foram premiados com a denominada "gratificação faroeste". A gratificação faroeste foi criada em 1995 pelo general Nilton Cerqueira, secretário de Segurança Pública no governo de Marcello Alencar. Esse tipo de prática fomentou a frequente ocorrência de confrontos e mortes e só foi suspensa no ano 2000. Para ver mais sobre a história das políticas de segurança pública e combate à violência do Rio de Janeiro, ver Silva e Menezes (2019). 
Para Vera Batista (2003, p. 25), o entendimento de que o Rio de Janeiro é uma cidade dividida ao meio acaba por contrapor asfalto e favela em termos de civilização e barbárie. Essa contraposição, que coloca a civilização como constituinte do lado do asfalto e a barbárie como caracterizadora das favelas, permite um zoneamento invisível do espaço urbano no Rio de Janeiro e promove a segregação entre o espaço dos "bárbaros" e o dos "civilizados". Por conseguinte, o "favelado" é automaticamente associado à criminalidade, devendo ficar confinado ao território das favelas. Estas últimas, por sua vez, tornam-se passíveis de políticas repressivas e de contenção marcadas pela tendência do aparato estatal brasileiro em recorrer ao racismo e ao higienismo como política pública.

A insegurança pública e a violência no Rio de Janeiro são desafios contínuos e constantemente caracterizados pelas autoridades públicas como uma guerra. ${ }^{29}$ Os termos utilizados são importantes, uma vez que a opção por empregar um vocabulário militar para se referir ao problema de segurança pública no Rio de Janeiro - com palavras como guerra, confronto, conflito armado, ocupação, pacificação - legitima o emprego da força militar nas favelas cariocas e amplia a distância social em termos de cidadania entre as populações "do morro" e "do asfalto". Todavia, apesar do problema histórico com a violência no Rio de Janeiro, somente a partir do início dos anos 2000 essa questão se tornou prioridade na agenda de segurança nacional brasileira (AZII, 2016, p. 593). A preocupação com a segurança no Rio de Janeiro acabou por se acentuar com a inserção da cidade no circuito internacional dos megaeventos esportivos no início dos anos 2000 - Jogos Panamericanos, em 2007; Jogos Militares, em 2010; Copa do Mundo, em 2014; Jogos Olímpicos, em 2016. Em consequência dos grandes eventos esportivos, o problema de segurança na capital carioca deixa de ser apenas uma preocupação local, passando a ser compartilhada com o poder federal e

29 Sérgio Cabral, ex-governador do Rio de Janeiro, em entrevista concedida ao portal G1 no ano de 2010, comentou que a invasão do Morro do Alemão pela Polícia Militar fluminense, em ação coordenada com a Polícia Civil, a Polícia Federal e as Forças Armadas era uma guerra. O termo é empregado sobretudo para justificar o pedido de permanência das Forças Armadas no local até 2011 (ISKANDARIAN, 2010, s.p.). 
com os organismos internacionais envolvidos na realização, sobretudo dos Jogos Olímpicos.

O relatório elaborado em 2007 pela Comissão de Avaliação do Comitê Olímpico Internacional (COI) para os Jogos de 2016 destacava que a segurança na cidade do Rio de Janeiro consistia na principal preocupação da organização. A Comissão de Avaliação enfatizava no relatório que "o Rio reconhece que enfrenta desafios de segurança e está realizando um projeto ambicioso para melhorar os recursos, a tecnologia e o treinamento de sua força policial até 2012" (IOC, 2009, s.p.). Em resposta, as autoridades cariocas destacaram os avanços alcançados na redução de crimes violentos no Rio de Janeiro nos anos anteriores em decorrência de uma mudança na abordagem da Secretaria de Segurança Pública estadual, que incluía programas de policiamento das comunidades e programas sociais voltados às periferias da cidade (IOC, 2009, s.p.) - uma clara referência à política de pacificação que seria oficialmente implementada no ano seguinte (AZZI, 2017, p. 598).

Em 2008, logo após a Federação Internacional de Futebol (Fifa) anunciar que o Brasil sediaria a Copa do Mundo de 2014, o governo federal e o do estado do Rio de Janeiro anunciaram a implementação da política de pacificação das favelas cariocas. A primeira UPP foi instalada na favela de Santa Marta, no bairro de Botafogo, e a última, na zona oeste do Rio de Janeiro, em 2014. As UPPs ${ }^{30}$ constituíam-se em uma estratégia de ocupação das favelas para promover o combate ao domínio do tráfico de drogas e à violência por meio do policiamento permanente desses espaços. O objetivo era recuperar a soberania nesses territórios, estabelecendo maior

30 Ao todo, "foram criadas 38 UPPs em 196 comunidades que reúnem cerca de 700 mil habitantes" (COELHO; PROVENZA, 2016, p. 3). As 30 UPPs estavam localizadas em: Santa Marta, Cidade de Deus, Batan, Chapéu Mangueira e Babilônia; Pavão-Pavãozinho e Cantagalo; Ladeira dos Tabajaras e Cabritos; Morro da Providência, Pedra Lisa e Moreira Pinto; Morro do Borel, Casa Branca, Chácara do Céu, Indiana, Morro do Cruz, Catrambi; Formiga; Morro do Andaraí, Nova Divinéia, João Paulo II, Juscelino Kubitschek, Jamelão, Morro Santo Agostinho e Arrelia; Salgueiro; Turano; Macacos; Quieto, São João e Matriz; Fallet, Fogueteiro, Coroa; Prazeres, Escondidinho; Morro São Carlos, Mineira, Zinco e Querosone; Mangueira; Vidigal e Chácara do Céu; Fazendinha; Nova Brasília; Morro do Adeus/Morro da Baiana; Alemão; Chatuba; Fé/Serrano; Vila Cruzeiro; Vila Proletária da Penha; Rocinha; Manguinhos; Jacarezinho; Barreira/Tuiti; Caju; Arará/Mandela; Cerro-Corá; Lins; Camarista Meier; Mangueirinha. 
presença do Estado. O discurso oficial enquadrou a conflitualidade da cidade do Rio de Janeiro como uma prioridade máxima na agenda de segurança nacional e defendeu o destacamento das Forças Armadas, cujo papel, a priori, é manter a integridade doméstica e proteger o país de ameaças externas.

O emprego das Forças Armadas no Rio de Janeiro não se constituía em um recurso inédito na cidade. De 1992 até 2018, foram realizadas 14 operações de garantia da lei e da ordem (GLO) na cidade - das quais seis atuaram na segurança pública e oito reforçaram a segurança da cidade para a realização de grandes eventos. Como consequência dessa frequente atuação em operações de GLO, as Forças Armadas brasileiras, principalmente o Exército, estão familiarizadas com técnicas militares de atuação em perímetro urbano e principalmente com a realidade carioca. ${ }^{31}$ As operações de GLO são previstas pela Constituição para os casos em que há o esgotamento das forças tradicionais de segurança pública, em graves situações de perturbação da ordem e/ou para a atuação na segurança de eventos importantes (BRASIL, 2020a, s.p.). Esse tipo de operação permite a utilização das Forças Armadas em situações que estão fora de suas responsabilidades tradicionais, concedendo provisoriamente aos militares a autorização para a atuação com poder de polícia. ${ }^{32}$ Cabe ressaltar que as GLOs, quando utilizadas em decorrência do aumento da violência, são operações que indicam, por si só, a falência das forças tradicionais da segurança pública em uma localidade. Portanto, elas deveriam se configurar como último recurso.

31 O general Carlos Alberto dos Santos Cruz afirmou, em entrevista concedida aos pesquisadores Celso Castro e Adriana Marques, que o Brasil já foi para o Haiti com a experiência em operações militares no perímetro urbano, de modo que para Santos Cruz (2018, p. 97), "não foi o Haiti que ensinou o pessoal [exército] a atuar em área urbana", foi o "Rio de Janeiro que nos ensinou a atuar em área urbana". Para o general, a experiência militar brasileira consolida-se com as operações de retomada e ocupação das favelas haitianas. Todavia, a constante participação do exército em GLOs é determinante para a construção de um conhecimento técnico sobre guerras irregulares. Dessa forma, pode-se observar que há um processo de transferência de conhecimento tanto do Brasil para o Haiti, como do Haiti para o Rio de Janeiro. Esse processo consolida a atuação cada vez mais frequente das Forças Armadas em operações realizadas no espaço urbano.

32 A GLO é obrigatoriamente um operação episódica, em área restrita e por tempo limitado, com o objetivo de preservar a ordem pública, a integridade da população e garantir o funcionamento regular das instituições. 
O emprego constante desse tipo de operação no Rio de Janeiro não indica apenas o aumento da violência e do poder dos traficantes e das milícias ${ }^{33}$ na cidade, mas revela a deterioração das instituições públicas responsáveis por lidar com a segurança nessa localidade.

No entanto, ao se dedicar um olhar mais atento às políticas de contenção da violência no Rio de Janeiro (incluindo a criação das UPPs) por meio do emprego das Forças Armadas, observa-se que esse tipo de prática configura uma característica histórica brasileira mais ampla: a utilização da violência pacificadora como mecanismo de integração social (SOUZA et al., 2017, p. 9). Desse modo, por mais que a política de pacificação brasileira esteja inserida em um contexto mais amplo de práticas e racionalidades - advindas do âmbito internacional -, ela ainda emana do Estado brasileiro, e a cujos interesses responde. Em consequência disso, as práticas pacificadoras operacionalizadas no Rio de Janeiro refletem um processo histórico simultaneamente nacional e internacional, sendo marcadas pela ascensão de um dispositivo de governo que está sustentado em quadros epistêmicos globais e nos processos históricos de formação do Estado brasileiro. Isso ocorre porque, em essência, as práticas e racionalidades presentes nas unidades de polícia pacificadora (UPPs) possuem um caráter marcadamente autoritário e normalizador - vinculado ao termo pacificação. A ideia de pacificação está presente ao longo da história brasileira, desde o período colonial até a atualidade, engendrando práticas de governamento verticalizadas e militarizadas das populações que são percebidas como perigosas, não civilizadas e "bárbaras" (OLIVEIRA, 2017, p. 55-56). Por conseguinte, o conflito é construído historicamente no território brasileiro desde a representação de uma relação de alteridade entre o agente pacificador e o "outro" a ser pacificado ${ }^{34}$ (OLIVEIRA, 2017, p. 57). Mais do que isso, a ideia

33 O levantamento feito pelo portal G1 em 2018, a partir de dados do Ministério Público Estadual e do Instituto Brasileiro de Geografia e Estatística (IBGE), apontava que mais de 2 milhões de pessoas na Região Metropolitana do Rio viviam em áreas sob influência das milícias (GRANDIN, 2018, s.p.).

34 Essa relação pode ser exemplificada a partir das práticas e políticas indigenistas brasileiras e como estas buscavam "pacificar" e disciplinar os índios descritos como "bravos" por meio das guerras justas e da tutela da Igreja e do Estado sobre eles (OLIVEIRA, 2017, p. 57). 
de pacificação é empregada historicamente pelo Estado brasileiro como instrumento de manutenção da unidade territorial por meio do uso da força. Dessa forma, a ideia de pacificação se converte em uma categoria nativa que possibilita que determinados territórios e grupos sociais sejam convertidos em alvos de práticas de repressão e controle por parte do Estado.

A lógica da ideia de pacificação está presente ao longo de toda história brasileira e se converte em um quadro discursivo que sustenta, apoia e forma práticas e racionalidades políticas nas mais diversas esferas - conectando, muitas vezes, práticas que se encontram aparentemente distantes. Nesse sentido, observa-se que o termo pacificação se configura em um ponto de conexão entre a política de pacificação no Rio de Janeiro e o modus operandi adotado pelas Forças Armadas brasileiras no comando da MINUSTAH. O Brasil esteve à frente do comando militar da Missão das Nações Unidas para estabilização do Haiti de 2004 a 2017. Durante esse período, as forças militares foram amplamente utilizadas para responder aos desafios advindos do domínio das regiões periféricas da capital haitiana, Porto Príncipe, por gangues. Nesse contexto, o Brasil se utilizou da sua experiência doméstica - marcada pela necessidade de responder à criminalidade urbana nas periferias brasileiras por meio das operações de garantia da lei e da ordem (GLOs) - ao lidar militarmente com o desafio representado pelas gangues em Porto Príncipe, no Haiti (SCHUBERTH, 2019, p. 505). No entanto, também é possível constatar que houve uma ampla incorporação do aprendizado técnico e operacional obtido com a participação brasileira na MINUSTAH às políticas de segurança pública do país (HARIG, 2018, p. 9; SCHUBERTH, 2019, p. 499). Em grande parte, a experiência brasileira no Haiti também repercutiu internamente ao ser incorporada na criação das UPPs. Todavia, a experiência brasileira no Haiti não deve ser entendida como um mero laboratório para a política de pacificação das favelas cariocas, uma vez que esta reflete um processo mais profundo de transferência de conhecimento e de acúmulo de experiência entre várias instâncias políticas (HARIG, 2018; SCHUBERTH, 2019). Nesse sentido, é possível observar que as 
UPPs incorporam, por um lado, táticas de policiamento e repressão tradicionalmente brasileiras e, por outro, tentam incluir as estratégias de construção da paz operadas pelas Nações Unidas em países pós-conflito - como a criação da UPP Social.

Em entrevista concedida aos pesquisadores Celso Castro e Adriana Marques, o general Augusto Heleno (2008, p. 37), ${ }^{35}$ ao comentar sobre a pacificação de Bel Air ${ }^{36}$ em 2005, ressalta a semelhança com a política de UPPs do Rio de Janeiro. ${ }^{37}$ De uma forma geral, Heleno destaca que a pacificação de Bel Air se baseava em uma operação de invasão para retomada do território dominado por grupos criminosos e instalação de uma companhia militar no terreno, de modo que o poder púbico pudesse manter o controle sobre a área (HELENO, p. 38). O general Carlos Alberto dos Santos Cruz (2018, p. 109-110), ${ }^{38}$ ao comentar sobre a sua participação na MINUSTAH, ressalta que as UPPs cariocas podem ser comparadas aos strong points ${ }^{39}$ utilizados no Haiti para pacificar Cité Soleil. ${ }^{40} \mathrm{De}$ forma geral, esses strong points permitiram que as forças de paz da ONU consolidassem posições estratégicas dentro de Cité Soleil e, a partir delas, ampliassem seu controle sobre o bairro. Assim, a estratégia de pacificação do Haiti, liderada por Santos Cruz, baseou-se na invasão e consequente ocupação dos bairros dominados por grupos armados por meio de táticas de enfrentamento. No entanto,

35 O general Heleno foi o primeiro force commander brasileiro na MINUSTAH, permanecendo no comando militar da operação de junho de 2004 a agosto de 2005.

36 Favela localizada na capital haitiana, Porto Príncipe, marcada pelo domínio de gangues e pela frequente ocorrência de crimes violentos, como sequestros e assassinatos. Bel Air foi a primeira favela a ser pacificada no Haiti por meio da retomada do território a partir do enfrentamento militar e da instalação de uma companhia permanente na localidade.

37 O general Heleno (2018, p. 38) destaca inclusive a presença da ONG brasileira Viva Rio no Haiti e do também coronel da Polícia Militar Ubiritan Angelo, que ocupava o cargo de coordenador de segurança humana do Viva Rio. É importante destacar que Ubiratan Angelo assumiu posteriormente o cargo de comandante-geral da Polícia Militar do Rio de Janeiro entre 2006 e 2007.

38 O general Santos Cruz foi o quarto force commander brasileiro na MINUSTAH, permanecendo no comando militar da operação de janeiro de 2007 a abril de 2009.

39 Na estratégia militar, strong points são pontos defensivos, fortemente armados, em torno dos quais outras posições estratégicas são agrupadas para que se possa consolidar a uma posição e dominar o terreno disputado.

40 Cité Soleil é um bairro periférico de Porto Príncipe. No momento da chegada das forças de paz da ONU no Haiti, esse bairro se encontrava dominado por gangues locais e era palco de confrontos entre gangues e práticas criminosas constantes. 
Santos Cruz ressalta que esse tipo de estratégia só será bem-sucedida se houver investimento dos poderes públicos no âmbito social e econômico da localidade ocupada militarmente. Para o general, esse foi o principal problema da política de pacificação na capital fluminense. De acordo com Santos Cruz (2018, p. 110), no Rio de Janeiro, "a UPP foi e ficou sozinha no meio de uma área conflitada”, não sendo acompanhada pelos serviços públicos. ${ }^{41}$

Os pesquisadores Castro e Marques (2019, p. 12) destacam que, no decorrer das entrevistas, é perceptível que, para os force commanders $^{42}$ entrevistados, o "Haiti é aqui", uma vez que são frequentes a associação e a comparação entre a situação de segurança pública no Haiti e no Rio de Janeiro. Em essência, os generais acreditam "numa via de mão dupla entre o que se aprendeu em experiências anteriores de emprego da força no Brasil - que antecedem a Missão no Haiti - e as que foram lá aplicadas" (CASTRO; MARQUES, 2019, p. 13). É consenso entre os entrevistados que o aprendizado no Haiti foi importante para aprimorar o emprego militar na segurança pública, incluindo as UPPs cariocas.

De forma muito semelhante ao modus operandi das forças de paz no Haiti, as UPPs são baseadas na invasão e ocupação das favelas cariocas. A criação do Programa de Pacificação do Rio de Janeiro emanou diretamente do Poder Executivo do estado e teve apoio direto do Poder Executivo federal. O programa foi promulgado como política apenas com o estabelecimento do Decreto-Lei $\mathrm{n}^{\circ}$ 42.787, de 6 de janeiro de 2011. Esse decreto foi publicado três anos após a instalação da primeira UPP em Santa Marta. Esse fato demonstra que a consolidação da política de pacificação não se deu de forma linear e, em certa medida, careceu de estruturação pública

41 Na opinião de Santos Cruz (2018, p. 113), as Forças Armadas, quando atuam na segurança pública, têm a finalidade apenas "dar uma cacetada na bandidagem, para o seu enfrentamento, para diminuir a sua ousadia", cabendo aos poderes públicos a continuidade do policiamento e de intervenção na esfera policial.

42 Foram entrevistados ao todo nove force commanders da MINUSTAH, entre eles: general Heleno, general Elito, general Santos Cruz, general Floriano Peixoto, general Paul Cruz, general Ramos, general Goulart, general Pujol e general Ajax. 
para sua implementação ${ }^{43}$ (FRANCO, 2018, p. 35). Todavia, diante do amplo interesse dos poderes públicos, tanto em nível municipal quanto estadual e federal, na promoção dessa política, as UPP acabaram se consolidando como a principal política de segurança pública direcionada ao combate à violência e ao tráfico de drogas entre os anos de 2008 e 2018. Desse modo, é possível perceber que a política de pacificação está intrinsecamente relacionada com a "guerra às drogas", com a proximidade dos Jogos Olímpicos e com a necessidade dos poderes públicos de atender às demandas da elite carioca por segurança e estabilidade (FRANCO, 2018, p. 68). Nesse sentido, as UPPs se constituíram em projeto que uniu atores e interesses variados, de modo que não surpreende sua permanência na agenda pública ao longo de vários governos. Por um lado, a política de pacificação respondia à necessidade urgente do governo federal, na época com os governos Lula e Dilma, em demonstrar para a comunidade internacional que a falta de segurança na cidade do Rio de Janeiro não seria um empecilho para a realização da Copa do Mundo e dos Jogos Olímpicos. Por outro lado, a pacificação das favelas cariocas era fundamental para o fortalecimento do governador do Rio de Janeiro diante da opinião pública do estado. Além desses elementos políticos, os interesses de grupos econômicos em adentrar as zonas da cidade ocupadas pelo tráfico configuravam-se

43 A política de pacificação tem como marcos regulatórios iniciais o Decreto-Lei n 41.650/2009, que dispôs sobre a criação da UPP dentro da Polícia Militar do Rio de janeiro. Já a Nota n 202, publicada em 5 de fevereiro de 2009 no Boletim da Polícia Militar, previa a desvinculação da UPP com o batalhão da área, vislumbrando promover a autonomia. E, em 5 de março de 2010, é aprovado o Regimento do Comando da Polícia Pacificadora, por meio da Portaria PMERJ no 337. Esses documentos, no entanto, não deixavam claro qual seria o escopo, os objetivos e os procedimentos da política. 
em incentivos importantes para o avanço e para a consolidação dessa política. ${ }^{44}$

Nesse contexto, o Decreto-Lei no 42.787/2011 foi responsável por delimitar as cinco etapas para a implementação das UPPs, que envolviam: $i$ ) a intervenção tática com o objetivo de retomar o controle sobre o território; ii) a estabilização do terreno pós-invasão; iii) a implantação e institucionalização da unidade; $i v$ ) a avaliação do desenvolvimento do trabalho de pacificação no terreno; e $v$ ) o monitoramento constante das ações promovidas pela unidade de pacificação. De acordo com Marielle Franco (2018, p. 37), a primeira etapa se caracterizava pela ocupação militar, com auxílio de tropas do Batalhão de Operações Especiais do Rio de Janeiro (BOPE/PMERJ), Batalhão de Polícia de Choque (BPChoque) e Forças Armadas, e/ou com a criação de um local com um comando e estrutura próprios. A segunda etapa se refere às estratégias de estabilização, intercalando as operações táticas e militares com interação na localidade. A terceira etapa diz respeito à implantação na localidade de uma política de proximidade permanente - com características de polícia comunitária. A quarta e a quinta etapa dizem respeito ao acompanhamento das ações implementadas pela polícia pacificadora dentro da favela.

Para que essas ações pudessem ser mais bem coordenadas, o governo do estado do Rio de Janeiro determinou a criação da Coordenadoria de Polícia Pacificadora (CPP), também por meio do Decreto no $42.787 / 2011 .^{45}$ Essa missão deveria ser realizada

44 De acordo com James Freeman (2012, p. 106) a pacificação das favelas do Rio de Janeiro, inegavelmente vinculada às estratégias de acumulação capitalistas (neo)liberal, teve os megaeventos esportivos como cerne da questão. Isso se deu porque a consolidação de uma estratégia que vise dirimir os efeitos da violência é fundamental para o marketing internacional dos jogos, assim como para o processo de preparar e construir a cidade para esses eventos. Dessa forma, as UPPs estiveram no centro da promoção de grandes negócios para a cidade e para os agentes internacionais envolvidos - a Fifa e o COI. Assim, como não seria possível erradicar as favelas, a solução encontrada é a sua inclusão no programa como em elemento exótico (VALENTE, 2016, p. 163). Para isso, é preciso transformar essas localidades em zonas seguras e livre do controle do tráfico de drogas por meio da pacificação. Além disso, Freeman (2012) destaca que a atuação dos poderes públicos em prol da população tem como efeito a valorização imobiliária no Rio de Janeiro e converte as favelas em commodities e mercado para as commodities. Por conseguinte, a "(re)conquista" das favelas possibilita que estas sejam alcançadas por negócios formais e empresas multinacionais.

45 A CPP tinha como missão dirigir as ações e operacionalizar o plano de implantação das UPPS. 
considerando as noções de eficácia, eficiência e efetividade, sem que houvesse a necessidade de reproduzir a gestão tradicionalmente militar. Assim, a administração do estado do Rio de Janeiro se propõe a fugir do policiamento convencional e altamente militarizado, delineando a instauração de uma política de proximidade com preocupações sociais. De acordo com as próprias definições oficiais, as UPPs constituíam-se em um novo modelo de segurança pública e de policiamento que tinha como objetivo a promoção de uma aproximação entre a população da favela e a polícia, aliada ao fortalecimento de políticas sociais nas favelas (OLERJ, 2015, p. 1). Esse mesmo documento delimitava que as UPPs tinham o objetivo de levar a paz às comunidades por meio da retomada do território. Todavia, essa disposição documental, como demonstra Franco (2018, p. 40), não garante a efetividade desse processo. Isso ocorre porque, dentro desse modelo de "pacificação", as políticas públicas sociais chegam em segundo plano e em determinadas regiões nem chegam (FRANCO, 2018, p. 41).

Muito embora as UPPs tivessem objetivos ampliados no que concerne à construção da paz no Rio de Janeiro, alinhando o discurso oficial a uma concepção de paz positiva ${ }^{46}$ (GALTUNG, 1969), na prática, foram observadas poucas iniciativas que de fato se direcionassem a modificar as estruturas sociais produtoras da desigualdade. A paz positiva não se limita apenas a refletir sobre o fim da violência direta de uma sociedade, mas também e principalmente na violência estrutural e nas desigualdades sociais (GALTUNG,

46 Tradicionalmente, a paz é compreendida tendo em conta a ocorrência ou a ausência da guerra. Em tal enquadramento a paz significa meramente a ausência de conflito. Todavia, para Galtung (1969, p. 171), a paz não está limitada a esses termos, envolvendo processos políticos e sociais mais profundos. Isso é possível porque o autor define a paz como a ausência de violência - onde a violência significa "a causa da diferença entre a realização potencial e a realização atual". Em decorrência desse entendimento, podemos falar na existência de formas de violência, sendo elas direta (pessoal), indireta (estrutural) e cultural. Assim, para o autor, a ausência de violência direta, ou seja, o estabelecimento de uma paz negativa, não seria capaz de eliminar a predisposição ao conflito ou à violência estrutural (GALTUNG, 1969, p. 183). O conceito de violência estrutural foi sintetizado pelo autor"como limitação das potencialidades de realização humana provocada por relações de poder, de desigualdade ou de opressão"(PUREZA, 2011, p. 10). A elucidação sobre a violência estrutural ilumina como a distribuição desigual dos recursos e do poder de decidir sobre esses recursos compunham um elemento essencial para se entender o surgimento de conflitos violentos. 
1969, p. 169). Para isso, a busca pela a paz positiva requer políticas que pensem a distribuição do poder e dos recursos, promovendo a igualdade de oportunidades entre os indivíduos (GALTUNG, 1967, p. 12). Desse modo, a noção de pacificação, em um primeiro momento, pode aparentar similaridade com as ideias de paz positiva e de construção da paz. Todavia, observando-se mais atentamente, nota-se que a pacificação se refere a uma prática de poder que incide sobre os indivíduos de forma muito mais tutelar e violenta (OLIVEIRA, 2017, p. 23). Dessa forma, a noção de pacificação está mais vinculada a uma concepção violenta de paz, que implica na derrota e na submissão à ordem social - representada pelo agente pacificador - dos indivíduos que são percebidos como bárbaros, incivilizados, perigosos ou conflituosos (OLIVEIRA, 2017, p. 11).

A intervenção pacificadora então possui, por um lado, um caráter civilizatório, que permite que ela seja apresentada como justa e legítima e, por outro, um caráter discriminatório, definidor daquilo que é socialmente aceitável ou não (OLIVEIRA, 2017, p. 11). Este último não apenas contribui para a marginalização dos grupos periféricos como possibilita o surgimento de práticas e ações de eliminação e higienização social dos elementos que não se submetem à ordem social vigente. De forma geral, as práticas de pacificação estão presentes no Brasil desde o período colonial, sendo direcionadas inicialmente aos povos indígenas brasileiros e, ao longo da história, aplicadas a diferentes grupos periféricos - negros, comunidades rurais, movimentos contestadores políticos e imigrantes (OLIVEIRA, 2017, p. 26). Essas práticas englobam uma "missão civilizadora da elite dirigente" frente a uma comunidade a ser pacificada.

Nesse sentido, as UPPs partiam da concepção de que era preciso: i) recuperar o território controlado pela criminalidade ostensivamente armada; e ii) devolver a essas comunidades a paz e a tranquilidade públicas necessárias ao seu desenvolvimento econômico e social (CARVALHO, 2018, p. 99). É possível notar que o primeiro objetivo engloba a noção de conquista, uma vez que delineia a necessidade da "recuperação" do território por meio do uso ostensivo da força. Nessa conjuntura, a polícia acaba figurando como 
a força reguladora e operadora da ordem dentro da favela e não há avanços significativos no que tange à desigualdade social e aos problemas estruturais das comunidades. Assim, nas favelas nas quais houve a instalação de UPPs, o governo era transferido para a polícia, que poderia tomar decisões quanto ao horário de circulação dos moradores, ao horário de funcionamento do comércio local e à realização de festas e eventos comunitários. O segundo objetivo, por sua vez, engendra um caráter tutelar por parte do Estado, delimitando a necessidade do reestabelecimento da ordem nas favelas por meio da ingerência do poder público. Este último ainda salienta a busca pelo desenvolvimento social nas localidades intervindas. Todavia, esse caráter foi subdesenvolvido no decorrer da política de pacificação, que se concentrou muito mais em uma gestão verticalizada e militarizada dos territórios das UPPs. Assim, as UPPs - que foram recebidas com otimismo pela sociedade carioca e pelos poderes públicos - rapidamente começaram a ser questionadas diante da sua baixa efetividade.

Isso foi possível porque o discurso dominante "reduziu o crime à sua dimensão mais visível e espetacular, o conflito aberto, enquanto a favela permanece estigmatizada como território de violência em potencial que demanda controle permanente" (BARREIRA, 2013, p. 151). Nesse contexto, fortalece-se a concepção de que a cidadania só poderá ser levada à favela por meio da gestão verticalizada e militarizada da mesma - as práticas pacificadoras (VALENTE, 2016, p. 21-22). A UPP, então, compartilha da visão da cidade partida e entende que o processo de ocupação e retomada desses territórios por vias militares é uma espécie de "libertação" dos indivíduos que vivem nessas localidades e de produção de cidadania (VALENTE, 2016). Todavia, a política de pacificação no Rio de Janeiro não está limitada aos problemas e particularidades da política e da sociedade carioca. Essa política está circunscrita em uma conjuntura histórica mais ampla e tipicamente brasileira, estando presente inclusive nas estratégias e práticas adotadas pelos force commanders brasileiros no Haiti. A pacificação, então, constitui-se numa racionalidade de governo - em termos foucaultianos como conduta da conduta - que 
dá suporte a práticas pacificadoras que, historicamente, baseiam-se no emprego da violência e no estabelecimento da tutela do Estado sobre grupos sociais percebidos como desviantes da norma social. Portanto, a ideia de pacificação joga luz sobre a base autoritária na qual está assente a governamentalidade do Estado brasileiro: a percepção de é que preciso pacificar via dominação militar para então promover uma "integração civilizadora" das populações periféricas. Esse entendimento, no entanto, cada vez mais converge para práticas e racionalidades políticas de âmbito internacional, principalmente no tocante aos mecanismos utilizados para a promoção da segurança nas cidades.

\section{Conclusão}

Este artigo analisou criticamente a política de pacificação das favelas cariocas por meio da criação das unidades de polícia pacificadoras (UPP). Tendo como base o referencial teórico foucaultiano, o argumento central consiste na ideia de que o processo de pacificação do Rio de Janeiro pode ser entendido como uma prática vinculada a mentalidades internacionais concernentes à segurança no âmbito das cidades. Nesse sentido, quadros epistêmicos como as concepções de cidade falida e do novo urbanismo militar acabam por informar e dar sustentação às práticas brasileiras de recuperação e ocupação das favelas cariocas. Dessa forma, as UPPs estão circunscritas a um arcabouço mais amplo de práticas e estratégias voltadas à compreensão e à resolução de conflitos - descritos como "assimétricos" ou de "baixa intensidade" - que ocorrem entre Estado e grupos contestadores dentro do perímetro urbano. A tendência internacional em se preocupar com essa "nova" modalidade de conflito engendra um novo conjunto de doutrinas e práticas militares direcionadas a informar a atuação estatal no âmbito das cidades. Essas práticas tendem a reproduzir as mentalidades táticas da guerra na gestão das cidades e acaba por militarizar a vida de suas populações. $\mathrm{O}$ controle e a vigilância, recorrentemente utilizados durante as guerras, é empregado dentro desse contexto para ampliar o controle e a vigilância sobre os indivíduos que podem ser 
considerados como suspeitos. Por conseguinte, as UPPs cariocas se constituíram em dispositivos de governo que buscavam modificar a estrutura da cidade de acordo, sobretudo, com a necessidade criada pela inserção do Rio de Janeiro no Jogos Olímpicos. Isso ocorreu, principalmente, porque, com a inclusão da cidade no circuito dos megaeventos esportivos, houve o surgimento de uma demanda internacional pela resolução das contradições sociais e dos problemas securitários da cidade.

Todavia, em essência, a UPP acabou por significar a crescente militarização da vida na cidade do Rio de Janeiro, em especial nas favelas cariocas. Dessa maneira, a operacionalização da política de pacificação no Rio de Janeiro parte de uma concepção que entende o Rio de Janeiro, ou pelo menos as favelas cariocas, como uma cidade falida. Esse entendimento fomentou a utilização do aparato militar como uma forma de responder à violência na cidade por meio de uma profunda intervenção, que não visava apenas a criminalidade na cidade, mas, sobretudo, o exercício do governo, como "conduta da conduta", da população das favelas cariocas. Nesse sentido, as UPPs se voltaram muito mais a práticas de governo, como condução das condutas, por meio do policiamento permanente das favelas, do que à construção de políticas públicas que visassem à diminuição das desigualdades no Rio de Janeiro. A categoria histórica de pacificação colaborou para a implementação de uma política de alteridade, na qual o "outro" - o favelado carioca - é tratado como um criminoso em potencial, tornando-se passível de políticas repressivas de correção por parte do Estado.

\section{Referências}

AGAMBEN, Giorgio. O que é dispositivo? Outra Travessia, Florianópolis, n. 5, p. 1-16, jul./dez. 2005.

ARSENAULT, Elizabeth Grimm; BACON, Tricia. Disaggregating and Defeating Terrorist Safe Havens. Studies in Conflict \& Terrorism, v. 38, n. 2, p. 85-112, 2014. 
APRAXINE, Pierre et al. (Org.). Urban violence and humanitarian challenges: joint report. Paris: Institute for Security Studies, 2012. Disponível em: https://www.iss.europa.eu/sites/default/files/ EUISSFiles/Urban_violence_and_humanitarian__challenges. pdf. Acesso em: 28 abr. 2020.

AZZI, Veronica F. Security for show? The militarisation of public space in light of the 2016 Rio Olympic Games. Contexto Internacional, v. 39, n. 3, p. 589-607, 2017. Disponível em: https:// www.scielo.br/pdf/cint/v39n3/0102-8529-cint-2017390300589. pdf. Acesso em: 28 abr. 2020.

BARREIRA, Marcos. Cidade olímpica: sobre o nexo entre reestruturação urbana e violência na cidade do Rio de Janeiro. In: BRITO, Felipe; OLIVEIRA, Pedro Rocha de. Até o último homem: visões cariocas da administração armada da vida social. São Paulo: Boitempo, 2013. p. 129-168.

BARROS, Rachel. Rio de Janeiro: o caleidoscópio da militarização urbana. 2018. In: LEITE, Márcia et al. Militarização no Rio de Janeiro: da pacificação à intervenção, p. 283-296. Rio de Janeiro: Mórula, 2018.

BATISTA, Vera Malaguti. O medo na cidade do Rio de Janeiro: dois tempos de uma história. Rio de Janeiro: Revan, 2003.

BELTRAME, José Mariano. Todo dia é segunda-feira. Rio de Janeiro: Sextante. 2014.

BLANCO, Ramon. Del mantenimiento de la paz al proceso de formación del Estado: un esbozo de los esfuerzos de la onu para la paz internacional. Foro Internacional 216, v. 54, n. 2, p. 266-318, abr./jun. 2014.

BLANCO, Ramon. Normalizando anormais na sociedade internacional: operações de paz, Foucault e a Escola Inglesa. Relações Internacionais, Lisboa, n. 53, p. 83-107, mar. 2017. BLANCO, Ramon. Peace as government: the will to normalize Timor-Leste. London: Lexington Books, 2020. 
BRASIL. Ministério da Defesa. Garantia da Lei e da Ordem. Brasília: Ministério da Defesa, 2020. Disponível em: https:// www.defesa.gov.br/exercicios-e-operacoes/garantia-da-lei-e-daordem. Acesso em 30 abr. 2020.

BRASIL. Ministério da Defesa. Tabela: histórico de GLOs. Brasília: Ministério da Defesa, 2020. Disponível em: https://www.defesa. gov.br/arquivos/exercicios_e_operacoes/glo/2.TABELAS_ GLO_atualizada_em_MAR_20.pdf. Acesso em: 30 abr. 2020.

CARVALHO, Monique Batista. Bem-aventurados os pacificadores: práticas de militarização e disciplinarização dos corpos nos programas de pacificação das favelas do Rio de Janeiro. In: LEITE, Márcia. et al. Militarização no Rio de Janeiro: da pacificação à intervenção, p. 92-110. Rio de Janeiro: Mórula. 2018.

CASTRO, Celso; MARQUES, Adriana. Missão Haiti: a visão dos force comamanders. Rio de Janeiro: FGV, 2019.

CHANDLER, David. Empire in denial: the politics of state building. London: Pluto Press, 2006.

CHOW, Rey. The age of the world target: self-referentiality in war, theory, and comparative work. Durhan: Duke University Press. 2006.

COElHO, Diogo; PROVENZA, Marcello (Org.). Balanço de indicadores da política de pacificação (20072015). Rio de Janeiro: ISP, 2016. Disponível em: http:// arquivos.proderj.rj.gov.br/isp_imagens/Uploads/ BalancodeIndicadoresdaPoliciadePacificacao2015.pdf. Acesso em: 30 abr. 2020.

DATA RIO. Rio em síntese: população e habitação. Rio de Janeiro: Instituto Pereira Passos, 2020. Disponível em: http://www.data. rio/pages/rio-em-sntese-2. Acesso em: 2 maio 2020.

DAVIS, Mike. Planet of slums. New York: Verso, 2006.

DEAN, Mitchell. Governmentality: power and rule in modern society. Londres: Sage Publications, 2010. 
DEAN, Mitchell. Risk, calculable and incalculable. In: LUPTON, Deborah (Ed.). Risk and sociocultural theory. New directions and perspectives. Cambridge: Cambridge University Press, 1999. p. 131-160.

DOLOWITZ, David; MARSH, David. Learning from abroad: the role of policy transfer in contemporary policy-making. Governance, v. 13, n. 1, p. 5-24, 2000.

DOLOWITZ, David. Transfer and learning: one coin two elements. Novos Estudos - Cebrap, São Paulo, v. 36, n. 1, p. 35-56, 2017.

DUFFIELD, Mark R. Development, security and unending war: governing the world of peoples. Cambridge: Polity, 2005.

EVANS, Mark; DAVIES, Jonathan. Understanding policy transfer: a multi-level, multi-disciplinary perspective. Public Administration, v. 77, n. 2, p. 361-385, 1999.

FOUCAULT, Michel. Microfísica do poder. Organização e tradução: Roberto Machado. 17. ed. Rio de Janeiro: Graal. 1979. FOUCAULT, Michel. Prisons et asiles dans le mécanisme du pouvoir. Dits et Ecrits, t. II. Paris: Gallimard, [1974]1994. p. 521-525.

FOUCAULT, Michel. Society must be defended. New York: Picador. ([1976] 2003).

FOUCAULT, Michel. The birth of biopolitics. Basingstoke:

Palgrave, Macmillan, [1978-1979] 2008.

FOUCAULT, Michel. Truth and power: an interview with Michel

Foucault. In: GORDON, Colin. (Ed.). Power/Knowledge.

Brighton: Harvester, 1980. p. 107-133.

FOUCAULT, Michel M. Vigiar e punir: nascimento da prisão.

Tradução: Raquel Ramalhete. Petrópolis: Vozes, 2014.

FRANCO, Marielle. UPP - Redução da favela a três letras: uma análise da política de segurança pública do Estado do Rio de Janeiro. Dissertação (Mestrado em Administração) Universidade Federal Fluminense, Rio de Janeiro, 2014. 
FREEMAN, James. Neoliberal acumulation strategies and the visible hand of police pacification in Rio de Janeiro. Revista de Estudos Universitários, Sorocaba, v. 38, n. 1, p. 95-126, jan./jun. 2012.

FUKUYAMA, Francis. Nation-building: beyond Afghanistan and Iraq. Baltimore: The Johns Hopkins University Press. 2005.

GRANDIN, Felipe et al. Franquia do crime: 2 milhões de pessoas no RJ estão em áreas sob influência de milícias. G1, Rio de Janeiro, 14 mar. 2018. Disponível em: https://g1.globo.com/rj/rio-dejaneiro/noticia/franquia-do-crime-2-milhoes-de-pessoas-no-rjestao-em-areas-sob-influencia-de-milicias.ghtml. Acesso em: 30 abr. 2020.

GALTUNG, Johan (1975) Peace: Research - Education - Action. Copenhagen: Chr. Ejlers Forlag. Essays in Peace Research.

GALTUNG, Johan. Violence, peace, and peace research. Journal of Peace Research, v. 6, n. 3, p. 167-191, 1969.

GORDON, Colin. Governmental rationality: an introduction. In: BURCHELL, Graham; GORDON, Colin; MILLER, Peter (Ed.). The Foucault effect: studies in governmentality. Chicago: University of Chicago Press, 1991.

GRAHAN, Stephen. Cidades sitiadas: o novo urbanismo militar. São Paulo: Boitempo, 2016.

HAMMES, Thomas X. The sling and the stone: on war in the $21^{\text {st }}$ century. Londres: Zenith Press, 2006.

HARIG, Christoph. Re-importing the 'robust turn' in UN peacekeeping: internal public security missions of Brazil's military. [S.l.], p. 1-45, 2018. Preprint de artigo publicado em: International Peacekeeping, v. 26, n. 2, p. 137-164, 2019.

HELENO. Entrevista com o General Augusto Heleno Ribeiro Pereira. In: CASTRO, Celso; MARQUES, Adriana. Missão Haiti: a visão dos force comamanders. Rio de Janeiro: FGV, 2019. p. 17-50.

HELMAN, Gerald B; RATNER, Steven R. Saving failed states. Foreign Policy, n. 89, p. 3-20, 1992. 
IEP - INSTITUTE FOR ECONOMICS \& PEACE. Global peace index 2019: measuring peace in a complex world. Sydney: IEP, 2019. Disponível em: http://visionofhumanity.org/app/ uploads/2019/06/GPI-2019-web003.pdf. Acesso em: 29 abr. 2020.

INSTITUTO IGARAPÉ. América Latina é região mais violenta do planeta, com 39\% dos homicídios. Rio de Janeiro: Instituto Igarapé, 2018. Disponívelem: Acesso em: https://bit.ly/3kAUEcK. 30 abr. 2020.

INSTITUTO IGARAPÉ. Cidades Frágeis: Instituto Igarapé, 2020. Disponível em: http://fragilecities.igarape.org.br/ expert/?uid=history-1576589266026-HJ9ADIURr. Acesso em: 30 abr. 2020.

IOC -INTERNATIONAL OLYMPIC COMMITTEE. Report of the 2016 IOC Evaluation Commission. Lausanne: IOC, 2009. ISKANDARIAN, Carolina. "É guerra”, diz Cabral sobre ocupação no complexo do Alemão. G1, Rio de Janeiro, 30 nov. 2010. Disponível em: http://g1.globo.com/rio-de-janeiro/rio-contrao-crime/noticia/2010/11/e-guerra-diz-cabral-sobre-ocupacaono-alemao.html. Acesso em: 30 abr. 2020.

JABRI, Vivienne. Peacebuilding, the local and the international: a colonial or a postcolonial rationality? Peacebuilding, v. 1, n. 1, p. 3-16, fev. 2013.

JOSEPH, Jonathan. The limits of governmentality: Social theory and the international. European Journal of International Relations, v. 16, n. 2, p. 223-246, 2010.

JÜTERSONKE, Oliver; MUGGAH, Robert; RODGERS, Dennis. Gangs, urban violence, and security interventions in Central America. Security Dialogue 40, n. 4-5, p. 373-97, 2009.

KOONINGS, Kees e KRUIJT, Dirk. Fractured cities: social exclusion, urban violence and contested spaces in Latin America. London: Zed Books, 2007. Disponível em: <http:// ir.nmu.org.ua/bitstream/handle/123456789/137051/ e2dd9df8d090c3cc710e6a540e7b7f2.pdf?sequence $=1>$ 
LEITE, Márcia Pereira. Entre a guerra e a paz: unidade de polícia pacificadora e gestão dos territórios de favela no Rio de Janeiro. Dilemas, v. 7, n. 4, p. 625-642, 2014.

LEITE, Márcia Pereira. Entre o individualismo e a solidariedade: dilemas da política e da cidadania no Rio de Janeiro. Revista Brasileira de Ciências Sociais, v. 15, n. 44, p. 43-90, 2000.

LEITE, Márcia et al. Militarização no Rio de Janeiro: da pacificação à intervenção. Rio de Janeiro: Mórula, 2018.

LEMKE, Thomas. An indigestible meal? Foucault, governmentality and state theory. Distinktion, n. 15, p. 43-64, 2007.

LIPSCHUTZ, Ronnie D. Power, politics and global civil society. Millennium, v. 33, n. 3, p. 747-76, 2005.

MAGNUSSON, Warren. Politics of urbanism: seeing like a city. Routledge: Londres. 2011

MIKLOS, Manoela; PAOLIELLO, Thomaz. Fragile cities: a critical perspective on de repertoire for new urban humanitarian interventions. Contexto Internacional, v. 39, n. 3, p. 545-568, set./dez. 2017. Disponível em: http://www.scielo.br/pdf/cint/ v39n3/0102-8529-cint-2017390300545.pdf. Acesso: 14 abr. 2019. MORAES, Joysi; MARIANO, Sandra R. H; FRANCO, Andrea Marinho de Souza. Unidades de polícia pacificadora (UPPs) no Rio de Janeiro: uma história a partir das percepções e reflexões do gestor responsável por sua implantação. Revista de Administração Pública, Rio de Janeiro, v. 49, n. 2, p. 493-518, 2015.

MUGGAH, Robert. Descontructing the fragility city: exploring insecurity, violence and resilience. Environment and Urbanization, v. 26, n. 2, p. 1-14, 2014.

MUGGAH, Robert. Researching the urban dilemma: urbanization, poverty and violence. Ottawa: IDRC, 2012. Disponível em: https://www.idrc.ca/sites/default/files/sp/Images/Researchingthe-Urban-Dilemma-Baseline-study.pdf. Acesso: 14 abr. 2019. 
MUGGAH, Robert; SAVAGE, Kevin. Urban violence and humanitarian action: engaging the fragile city. The Journal of Humanitarian Assistance, 19 jan. 2012. Disponível em: https:// sites.tufts.edu/jha/archives/1524. Acesso: 14 abr. 2019.

NEAL, Andrew. Michel Foucault. In: EDKINS, Jenny; VAUGHANWILLIAMS, Nick (Ed.). Critical theorists and international relations. London: Routledge. 2009.

NEUMANN, Iver B; SENDING, Ole Jacob. Governing the global polity: practice, mentality, rationality. University of Michigan Press: Michigan. 2010.

NOGUEIRA, João Pontes. From failed states to fragile cities: redefining spaces of humanitarian practice. Third World Quarterly, v. 38, n. 7, p. 1437-1453, 2017.

NORTON, Richard J. Feral cities - The New Strategic Environment.

Naval War College Review, v. 56, n. 4, p. 97-106, 2003.

OLERJ - OBSERVATÓRIO LEGISLATIVO DA INTERVENÇÃO FEDERAL NA SEGURANÇA PÚBLICA DO RIO DE JANEIRO. Unidade de Polícia Pacificadora. Rio de Janeiro: Olerj, [2015]. Disponível em: http://olerj.camara.leg.br/retratosda-intervencao/unidade-de-policia-pacificadora-upp. Acesso: 14 abr. 2019.

OLIVEIRA, João Pacheco de. Uma guerra sem fim: a retórica da pacificação e práticas institucionalizadas de produção da desigualdade. In: SOUZA, Adriana Barreto de et al. (Org.). Pacificar o Brasil: das guerras justas às UPPs. São Paulo: Alameda, 2017.

OLIVEIRA, João Pacheco de. Pacificação e tutela militar na gestão de populações e territórios. Mana, Rio de Janeiro, v. 20, n. 1, p. 125-161, 2014.

PUREZA, José Manuel. O desafio crítico dos estudos para a paz. Relações Internacionais, n.32, p. 5 22, 2011. Disponível em: < http://www.scielo.mec.pt/pdf/ri/n32/n32a01.pdf>. Acesso em: 12/03/2020. 
ROLIM, Louise. Segurança pública em números 2019: evolução dos principais indicadores de criminalidade e atividade policial no estado do Rio de Janeiro de 2003 a 2019. Rio de Janeiro: ISP, 2020. Disponível em: http://arquivos.proderj.rj.gov.br/isp_ imagens/Uploads/SegurancaEmNumeros2019.pdf. Acesso em: 30 abr. 2020.

ROSE, Nikolas. Powers of freedom: reframing political thought. Cambridge: Cambridge University Press, 2004.

ROSENAU, James. Governança, ordem e mudança na política mundial. In: ROSENAU, James N.; CZEMPIEL, Ernst-Otto (Org.). Governança sem governo: ordem e transformação na política mundial. Brasília, DF: Unb. 2000.

ROTBERG, Robert. The new nature of nation-state failure. The Washington Quarterly, v. 25, n. 3, p. 85-96, 2002.

SANTOS CRUZ. Entrevista com o General Carlos Alberto dos Santos Cruz. In: CASTRO, Celso; MARQUES, Adriana. Missão Haiti: A visão dos force comamanders. Rio de Janeiro: FGV, 2018. p. 75-114.

SCHUBERTH, Moritz. Brazilian peacekeeping? Counterinsurgency and police reform in Port-au-Prince and Rio de Janeiro. International Peacekeeping, v. 26, n. 4, p. 487-510, 2019.

SENDING, Ole Jacob; NEUMANN, Iver B. Governance to governmentality: analyzing NGOs, states, and power. International Studies Quarterly, v. 50, n. 3, p. 651-672, 2006.

SILVA; Luiz Antonio Machado da; LEITE, Márcia Pereira. Violência, crime e polícia: o que os favelados dizem quando falam desses temas? In: SILVA, Luiz Antonio Machado da (Org.). Vida sob cerco: violência e rotina nas favelas do Rio de Janeiro. Rio de Janeiro: Nova Fronteira, 2008.

SILVA, Luiz Antonio Machado da; MENEZES, Paloma Valle. (Des)continuidades na experiência de "vida sob cerco" e na "sociabilidade violenta”. Novos Estudos - Cebrap, São Paulo, v. 38, n. 3, p. 529-551, 2019. Disponível em: https://www.scielo. br/pdf/nec/v38n3/1980-5403-nec-38-03-529.pdf. Acesso em: $1^{\circ}$ maio 2020. 
SODRÉ, Muniz. Violência, mídia e política. In: FEGHALLI, Jandira; ALMEIDA, Cândido Mendes de; LEMGRUBER, Julita et al. Reflexões sobre a violência urbana: (in)segurança e (des) esperanças. Rio de Janeiro: Mauad, 2006.

SORENSEN, Georg. Failed states and international security II: Sources of prevention, modes of response, and conditions of state success and renewal. West Lafayette: Purdue University, abr. 1999. Disponível em: http://mstohl.faculty.comm.ucsb.edu/ failed_states/1999/papers/Sorensen.html. Acesso em: $1^{\circ}$ maio 2020.

SOUZA, Adriana Barreto de et al. Uma nação ordeira: a longa história da violência pacificadora no Brasil. In: SOUZA, Adriana Barreto de et al. (Org.). Pacificar o Brasil: das guerras justas às UPPs. São Paulo: Alameda, 2017.

STONE, Diane. Transfer agents and global networks in the 'transnationalization' of policy. Journal of European Public Policy, v. 11, n. 3, p. 545-566, 2004.

THE WORLD'S most violent cities. The Economist, 3 fev. 2016. Disponível em: https://www.economist.com/graphicdetail/2016/02/03/the-worlds-most-violent-cities. Acesso em: 14 jun. 2020.

THE WORLD'S most violent cities. The Economist, 3 mar. 2017. Disponível em: https://www.economist.com/graphicdetail/2017/03/31/the-worlds-most-dangerous-cities. Acesso em: 14 jun. 2020.

TRANSPARENCY INTERNATIONAL. The corruption perceptions index 2019. Berlim: Transparency International, 2019. Disponível em: https://www.transparency.org/ cpi2019\#report. Acesso em: 30 abr. 2020.

UN - UNITED NATIONS. World urbanization prospects: the 2018 revision. New York: UN, 2019. Disponível em: https:// population.un.org/wup/Publications/Files/WUP2018-Report. pdf. Acesso em: 28 abr. 2020. 
UN - UNITED NATIONS. Transforming our world: the 2030 agenda for sustainable development A/RES/70/1. New York: UN, 2019. Disponível em: https://sustainabledevelopment. un.org/content/documents/21252030\%20Agenda\%20for $\% 20$ Sustainable\%20Development\%20web.pdf. Acesso em 29 abr. 2020.

VALENTE, Júlia Leite. UPP's: governo militarizado e a ideia de pacificação. Rio de Janeiro: Revan, 2016.

VENTURA, Zuenir. Cidade partida. São Paulo: Companhia das Letras, 1994.

YAZDANI, Mariam; BERCOVITCH, Daniela; CHARLESVOLTAIRE, Jane. Knowledge transfer on urban violence: from Brazil to Haiti. Environment \& Urbanization, v. 26, n. 2, p. 457-468, 2014.

ZANOTTI, Laura. Governing disorder: UN peace operations, international security, and democratization in the post-Cold War Era. Pennsylvania: Pennsylvania State University Press, 2011.

ZANOTTI, Laura. Governmentality, ontology, methodology: re-thinking political agency in the global. Alternatives: Global, Local, Political, v. 38, n. 4, p. 288-304, 2013.

ZANOTTI, Laura. Imagining democracy, building unsustainable institutions: the UN peacekeeping operation in Haiti. Security Dialogue, v. 39, n. 5, 2008.

\section{Resumo}

Este artigo analisa como o conceito de"cidade falida"contribui para delimitar as cidades como um novo espaço de ingerência da governamentalidade global. Para evidenciar essa relação, o artigo analisa as iniciativas de pacificação promovidas no Rio de Janeiro a partir de 2008 com a criação das unidades de Polícia Pacificadora (UPPs). O caso é analisado sob a luz das contribuições teóricas e conceituais desenvolvidas por Michel Foucault e da ideia de governamentalidade global. O argumento central deste trabalho consiste na ideia de que as UPPs se constituíram em dispositivos de governo altamente militarizados com o objetivo de pacificar as favelas cariocas por meio da sua ocupação territorial e pelo estabelecimento 
de um regime de policiamento permanente. Esses dispositivos, por sua vez, estão relacionados com práticas e racionalidades nacionais e internacionais direcionadas ao controle da vida nas cidades, consideradas violentas e instáveis, como forma de pacificação das mesmas.

Palavras-chave: cidades falidas, pacificação, UPP, governamentalidade global.

\section{Abstract}

This article analyzes how the concept of "failed city" contributes to the definition of cities as spaces for interference by global governmentality. To highlight this relationship, the article analyzes the pacification initiatives promoted in Rio de Janeiro since 2008 through the creation of the Pacifying Police Units (UPPs). The case is analyzed through the theoretical and conceptual lens of Michel Foucault and the idea of global governmentality. The central argument of this article is that the UPPS were highly militarized government devices that had the objective of pacifying the favelas of Rio de Janeiro through territorial occupation and the establishment of a permanent policing regime. These devices, in turn, are related to national and international practices and rationalities aimed at controlling life in cities, considered violent and unstable, as a way of pacifying them.

Keywords: failed cities, pacification, UPP, global governmentality.

Recebido em 19 de fevereiro de 2020

Aprovado em 11 de junho de 2020 